NISTIR 7707

September 24, 2010

\title{
Virtual Cement and Concrete Testing Laboratory
}

\section{Educational Version 2.0 User Guide}

\author{
Jeffrey W. Bullard ${ }^{*}$ \\ Materials and Construction Research Division \\ National Institute of Standards and Technology \\ Gaithersburg, Maryland USA 20899-8615
}

This document serves as the user's guide for the educational version of the Virtual Cement and Concrete Testing Laboratory (VCCTL) software, version 2.0. Using the VCCTL software, a user may create 3D microstructures of cement paste made with clinker, calcium sulfate, fly ash, slag, limestone, and other materials. Hydration of these microstructures can be simulated under a variety of curing conditions, and the resulting hardened material can be analyzed for a number of properties including linear elastic moduli, compressive strength, and relative diffusion coefficients. A 3D packing of fine and coarse aggregates in mortar and concrete materials also can be created. The VCCTL software uses a relational database and plotting capabilities to facilitate viewing important characteristics of cement powders, supplementary cementitious materials, fillers, and aggregates. Finally, version 2.0 of the software gives the user control of the execution of his or her simulations.

Keywords: Building technology, cement hydration, computer modeling, concrete testing, microstructure, simulation, virtual laboratory

*Email address: jeffrey.bullard@nist.gov 



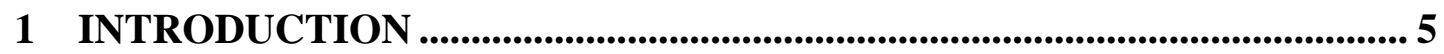

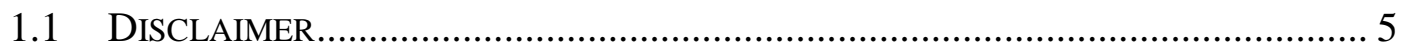

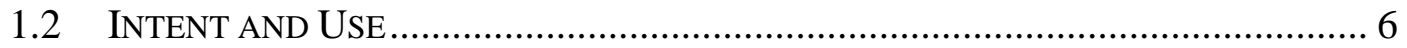

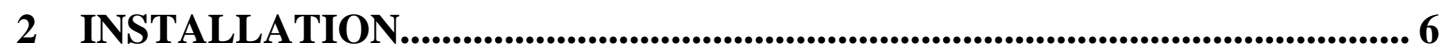

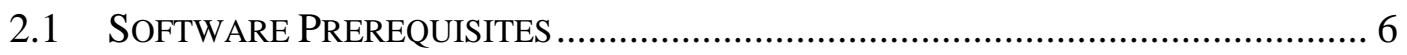

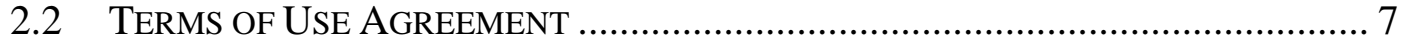

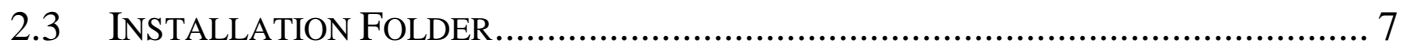

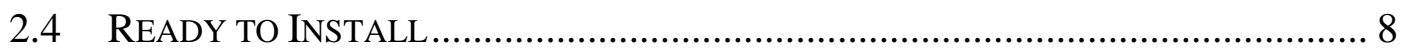

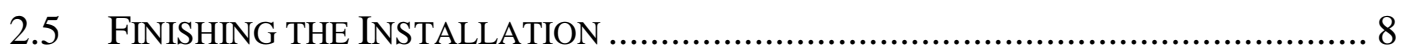

3 LAUNCHING AND CLOSING A SESSION ............................................... 9

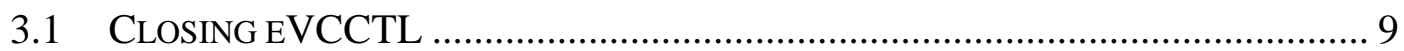

4 REGISTERING AND LOGGING ON ...................................................... 10

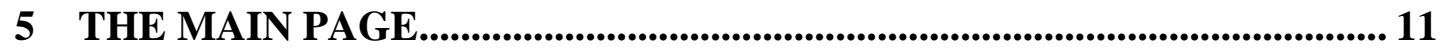

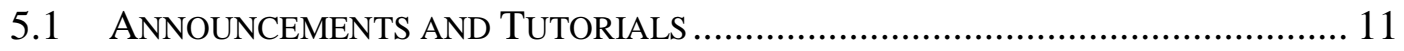

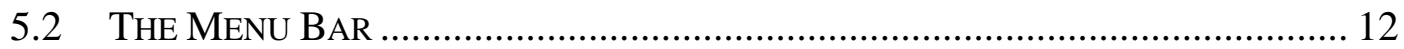

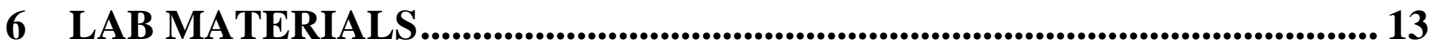

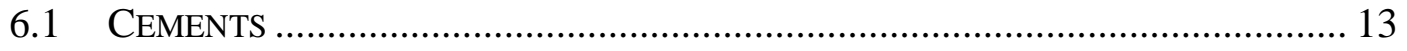

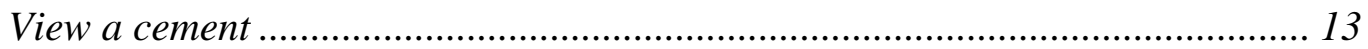

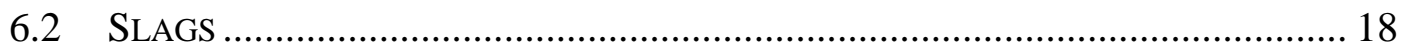

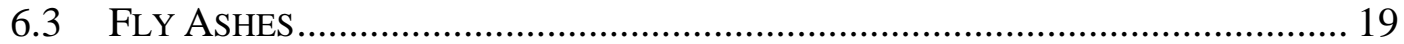

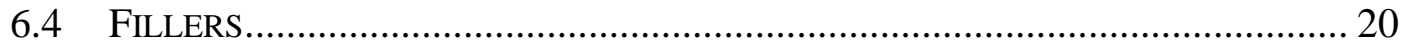

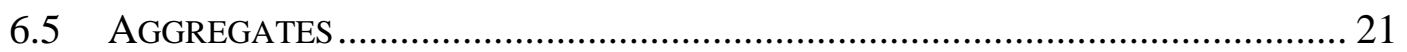

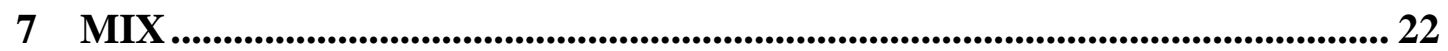

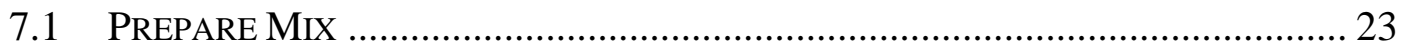

Specifying the solid cementitious binder ....................................................... 23

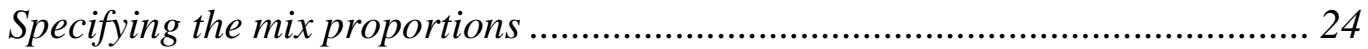

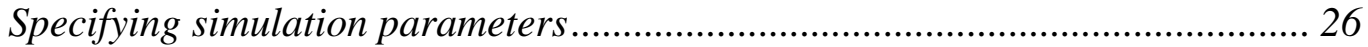

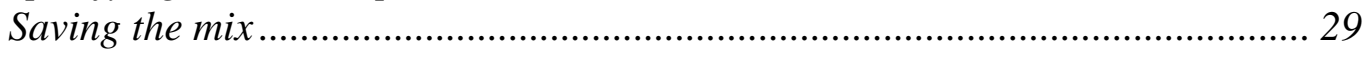

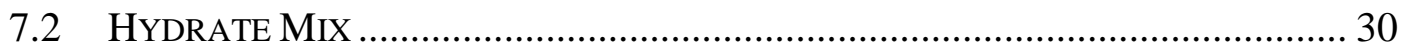




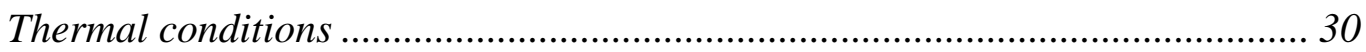

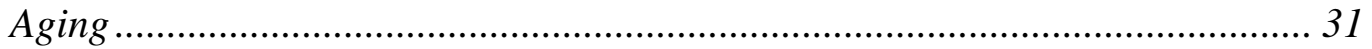

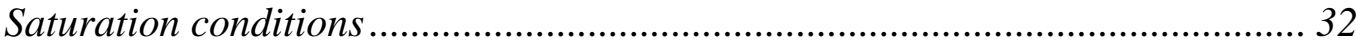

Simulation parameters .......................................................................... 32

Executing the hydration simulation .............................................................. 33

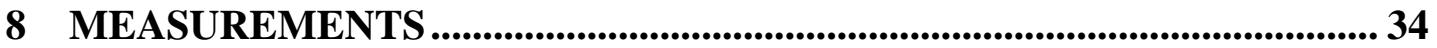

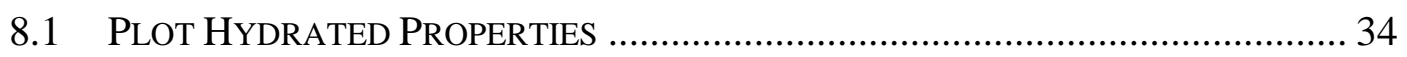

8.2 MeAsure CEMENT/ConCRETE Properties ................................................... 36

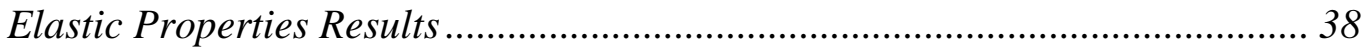

Transport Properties Results ........................................................................ 39

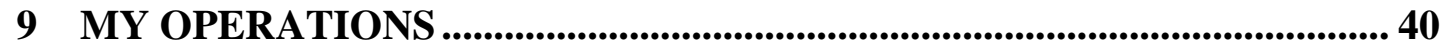

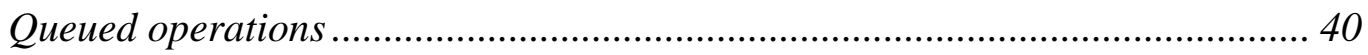

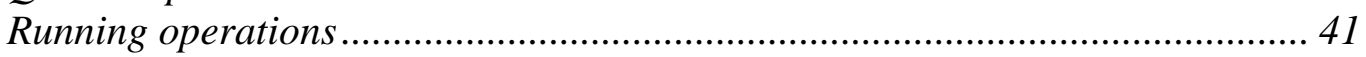

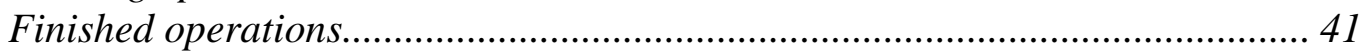

Canceled operations .............................................................................. 42

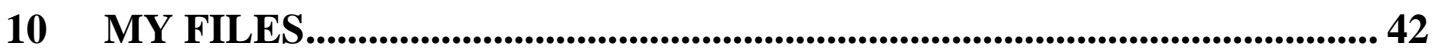

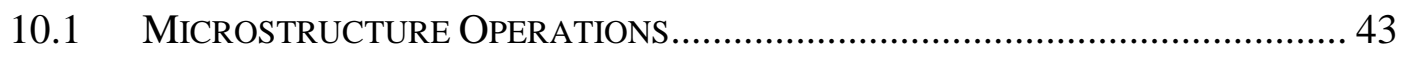

10.2 DISPLAYING MICROSTRUCTURE IMAGES .............................................. 45

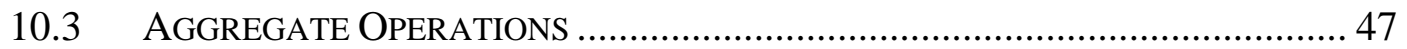

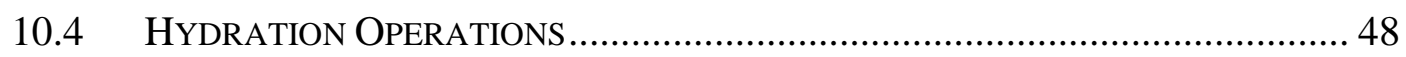

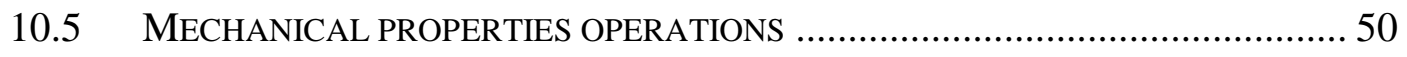

10.6 TRANSPORT PROPERTIES OPERATIONS ............................................... 51

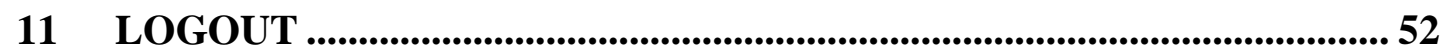

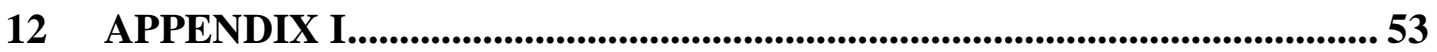

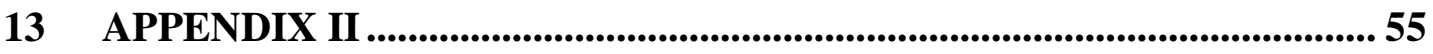

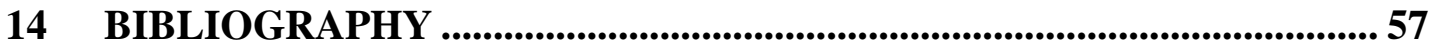




\section{Introduction}

This user's guide provides guidance for using the Virtual Cement and Concrete Testing Laboratory software, Educational Version 2.0 (eVCCTL 2.0). This virtual laboratory software consists of a graphical user interface and the underlying computer models and programs that allow users to create, hydrate, and estimate the performance of 3D cement-based microstructures from a desktop computer. The primary intent of this version is educational, especially to supplement the classroom experience of students studying civil engineering materials technology and materials science.

The main underlying programs for the eVCCTL software have been described previously [Bentz 1997, Bentz 2005, Garboczi 1998], and a large number of applications of these models has been published [Bentz and Haecker 1999, Bentz and Garboczi 1999, Bentz and Jensen 2000, Bentz and Feng, 2000, Bentz and Conway 2001, Bentz and Garboczi 1991, Bullard and Stutzman 2006, Bullard and Garboczi 2006]. This user guide therefore provides a detailed description of the user interface and a few examples of using eVCCTL for educational purposes.

\subsection{Disclaimer}

This software was developed at the National Institute of Standards and Technology (NIST) by employees of the Federal Government in the course of their official duties. Pursuant to Title 17 Section 105 of the United States Code this software is not subject to copyright protection and is in the public domain. The eVCCTL is an experimental system. NIST assumes no responsibility whatsoever for its use by other parties, and makes no guarantees, expressed or implied, about its quality, reliability, or any other characteristic. We would appreciate acknowledgment, such as an appropriate citation in a publication, if the software is used.

The U.S. Department of Commerce makes no warranty, expressed or implied, to users of eVCCTL and associated computer programs, and accepts no responsibility for its use. Users of eVCCTL assume sole responsibility under Federal law for determining the appropriateness of its use in any particular application; for any conclusions drawn from the results of its use; and for any actions taken or not taken as a result of analyses performed using these tools.

Users are warned that eVCCTL is intended for educational use only and is intended only to supplement the informed judgment of the user. The software package contains computer models which may or may not have predictive value when applied to a specific set of factual circumstances. Lack of accurate predictions by the models could lead to erroneous conclusions with regard to materials selection and design. All results should be evaluated by an informed user. 


\subsection{Intent and Use}

The algorithms, procedures, and computer programs described in this guide constitute a prototype system for a virtual laboratory for the testing of cement and concrete. They have been compiled from the best knowledge and understanding currently available, but have important limitations that must be understood and considered by the user. eVCCTL is intended for use by persons competent in the field of cement-based materials and having some familiarity with computers

\section{Installation}

\subsection{Software Prerequisites}

The following requirements must be met for successful installation and running of this distribution of eVCCTL:

Microsoft Windows XP computer ${ }^{1}$ (Service Pack 3). Other versions of Windows, such as Windows Vista or Window 7, may or may not be compatible with eVCCTL. Distributions are available for Linux operating systems; please contact the author for details.

A minimum of $2 \mathrm{~GB}$ RAM and minimum hard disk space of $20 \mathrm{~GB}$ for long-term use of the software. Multiprocessor architectures with expanded shared memory, such as $16 \mathrm{~GB}$, are commonly available and are recommended for the simultaneous execution of multiple simulations without loss of performance.

Java Development Kit (JDK) 1.6, Update 20, or a more recent update. Go to http://www.oracle.com/technetwork/java/javase/downloads/jdk6-jsp$136632 . \mathrm{html}$ to download the latest release of the JDK and follow the installation instructions given there.

Mozilla Firefox web browser, Version 3.0. Not required for installation, but other non-standard web browsers, such as Microsoft's Internet Explorer, give erratic results when running the software.

To install eVCCTL, drag the evcct l-2. $\odot$-installer -windows . exe icon to the Desktop. Once it has been copied to the Desktop, double-click on the installation icon. A series of windows will guide you through the installation process as follows.

1 Certain commercial equipment and/or materials are identified in this report in order to adequately specify the experimental procedure. In no case does such identification imply recommendation or endorsement by the National Institute of Standards and Technology, nor does it imply that the equipment and/or materials used are necessarily the best available for the purpose. 
Installation

\subsection{Terms of Use Agreement}

This dialog requires you to acknowledge the software disclaimer. If you accept the disclaimer agreement, you proceed with the installation by pressing the "Next" button. Otherwise, you will not be able to install and use the eVCCTL software.

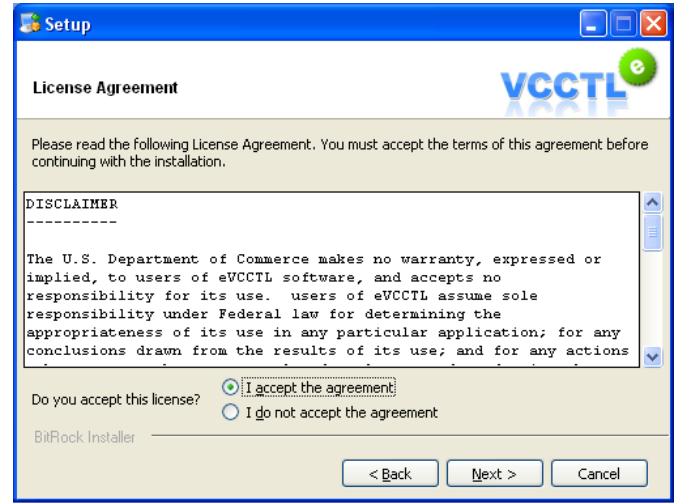

\subsection{Installation Folder}

You may install eVCCTL in any location on your computer, provided that you have the adequate read/write permissions. The default path and folder is C: \Program Files \vcctl. You may accept that default or change it to another location. However, THE FINAL FOLDER ON THE PATH MUST BE NAMED vcct 1 IN ALL LOWERCASE LETTERS. The software will not work properly if it is not installed in a folder named vcctl.

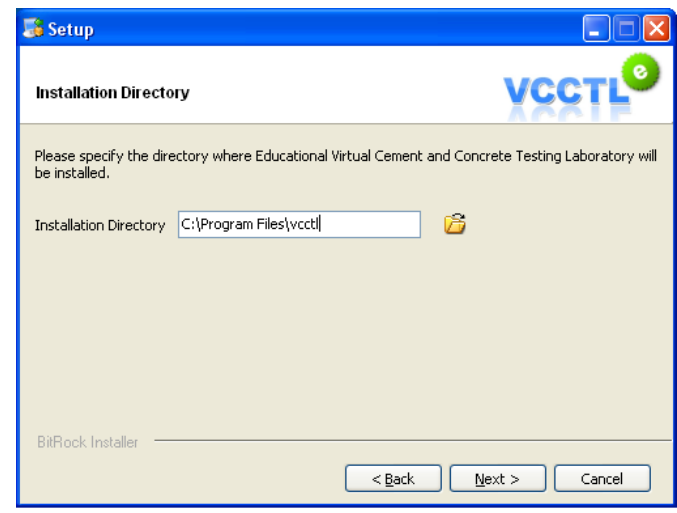


Installation

\subsection{Ready to Install}

The next dialog indicates that the software is ready to install. Clicking the "Next" button will begin the installation.

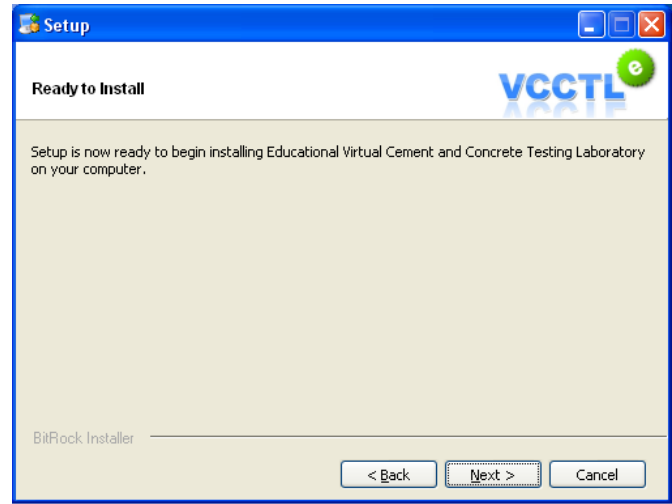

The last step of the installation is to unpack a rather large data folder. This step can consume several minutes, during which time it will appear that nothing is happening. Please be patient while the data folder unpacks.

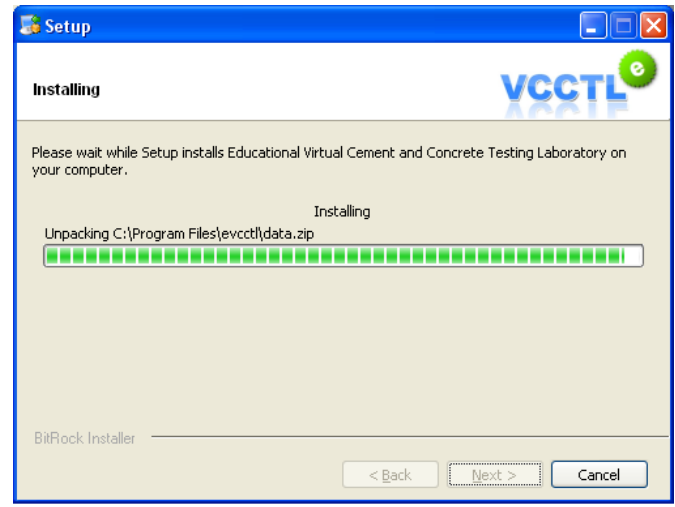

\subsection{Finishing the Installation}

When the final step is completed, a final dialog box will appear. Just click on the "Finish" button to close this dialog box. 


\section{Launching and Closing a Session}

Before running eVCCTL for the first time, it is helpful to make Mozilla Firefox your default web browser. To do this, open Mozilla Firefox. If it is not already your default browser, a dialog box should appear asking you if you want to make it your default browser. Click "Yes" and then close the browser after it opens.

If the installation was successful, then eVCCTL can be launched from the Desktop by double-clicking on the Desktop icon labeled eVCCTL 2.0:

\section{䆖得 \\ EVCCTL 2.0}

A Java console window will appear on the desktop, with a lot of information scrolling through it:

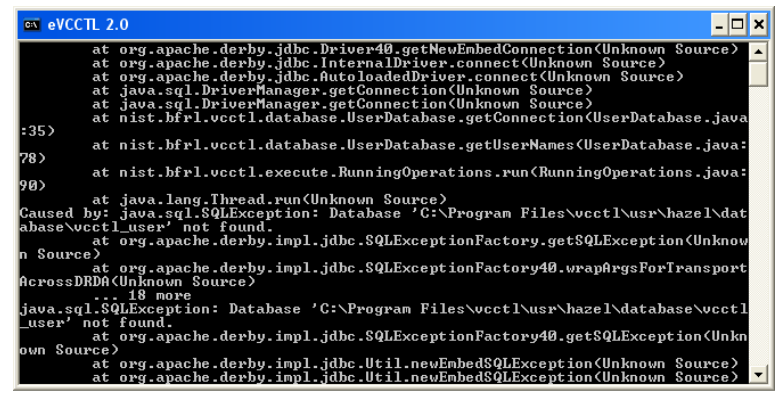

You must never close this console window while eVCCTL is running. Under ordinary circumstances, you may ignore this console window entirely. You may even minimize the window to your desktop tray if desired, but do not close it.

WARNING: You must never close the Java console window during an active session of eVCCTL. Doing so will cause eVCCTL to terminate immediately and, in some cases, a portion of the database that keeps track of your running operations may also become corrupted. It is safest to simply minimize the console window to your desktop tray and leave it there while you are using eVCCTL.

A few moments after the Java console window appears, your default web browser should open to the main login page of eVCCTL. Again, if this is not Mozilla Firefox, then you could observe unexpected or erratic behavior.

\subsection{Closing eVCCTL}

To properly shut down eVCCTL, follow these steps: 
1. Wait for all running operations to finish. Alternatively, you could cancel all the running operations if needed (this will be described in detail below).

2. Close the web browser

3. Open the Java console window and press Ctrl-C. After a brief pause, you will be asked, "Terminate batch job ( $\mathrm{Y} / \mathrm{N})$ ?". Type " $\mathrm{y}$ " and press the Enter button. The Java console window will close.

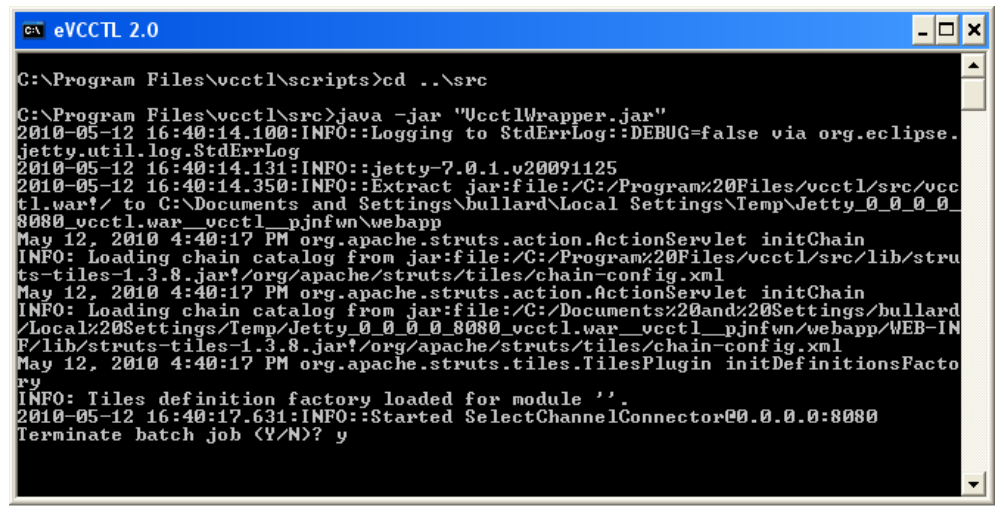

\section{Registering and Logging On}

eVCCTL is a standalone desktop application, but it allows for some form of data privacy among multiple users on the same computer. For this reason, a session begins with logging on with a user name and password.

Connection
Login: bullard Password: $\cdots . . . . .$.

Don't have an account? Register!

The first time you launch a session, you will not have a user name or password, so you must register with the database by clicking on the "Register!" link. This link will take you to a registration form shown below:

Enter your desired user name in the first box. If the user name is valid and has not been taken by someone else, you will see a green checkmark as shown. Otherwise, a red X will appear and you will be prompted to choose another name.

Next, enter your desired password. You must confirm the password in the adjacent text field, and if the two text fields agree, you will again see a green checkmark as shown.

Finally, enter your e-mail address in the bottom text box and confirm the address in the adjacent text box. E-mail addresses are not currently used by the 
application, but may be used in a future release to remotely notify users of completed operations, errors, or other important events.

When all the information has been entered properly (i.e., green checkmarks everywhere) then click the "Submit my registration" button. You will then be taken back to the login page, where you can enter your new user name and password.

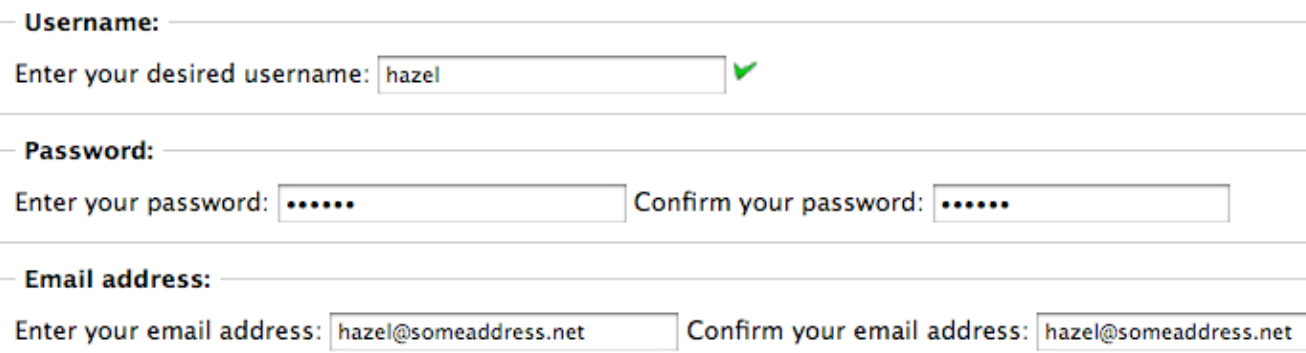

\section{The Main Page}

A successful login will open the main page of the application. There are two parts to this page: (1) a section for announcements and streaming video tutorials, (2) a running Menu Bar in gray near the top.

\subsection{Announcements and Tutorials}

This section briefly introduces you to the major features of the eVCCTL application and also features a "Lab Tour". The lab tour consists of a series of streaming video tutorials designed to step you through each of the major features and acquaint you with the procedures for running and monitoring different operations. Note that the lab tour requires (1) an internet connection and (2) a QuickTime plugin or other compatible streaming video plugin for your browser. Downloading and installing Apple's free QuickTime player should automatically update your browser with the plugin.

The tutorials and this user guide are designed to be used together. One should view the tutorials first, then consult this guide for further details. 


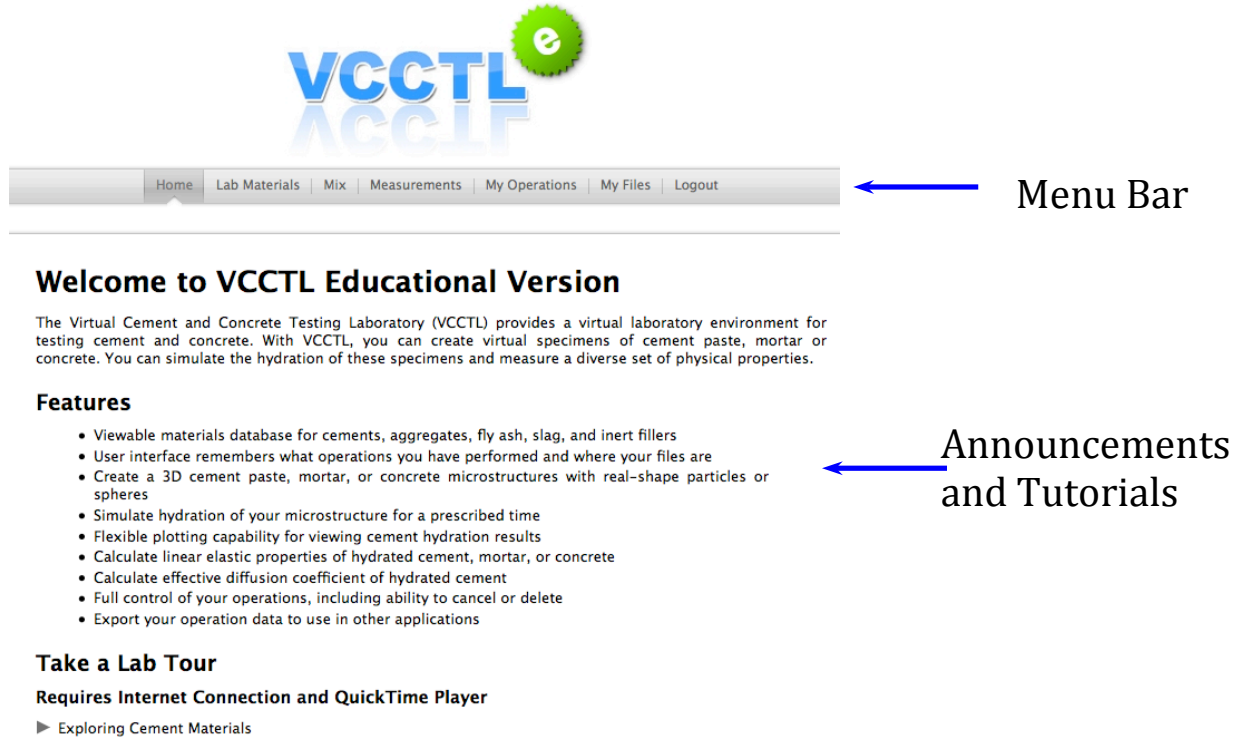

\subsection{The Menu Bar}

The menu bar is a persistent feature on all pages of the eVCCTL application, and enables you to quickly navigate from one part of the lab to another. The menu items are:

Home: The main page

Lab Materials: A multi-part page enabling you to examine the different materials stored in the eVCCTL database

Mix: A two-part page where you can make and hydrate virtual mixes of cement paste, mortar, or concrete

Measurements: A two-part page enabling you to plot the changes in properties of a material as it hydrates, or to calculate the linear elastic properties, compressive strength, and transport properties of your mix.

My Operations: Enables you to view the state of your requested operations (queued, running, finished, or canceled)

My Files: A listing of all your operations, complete with the ability to view any file in any operation or to export any file for further analysis by another application.

Logout: Provides a way to logout of the system or switch users.

Each of these menu items will be described in detail in the following sections. 


\section{Lab Materials}

Click on the "Lab Materials" tab on the main menu, and you will be taken to a page that has a submenu with five tabs:

\begin{tabular}{|l|l|l|l|l|}
\hline Cements & Slags & Fly Ashes & Fillers & Aggregates \\
\hline
\end{tabular}

Each tab takes you to a page that enables you to view the properties of the relevant material component in the eVCCTL database.

\subsection{Cements}

This page enables you to view the inventory of cements stored in the eVCCTL database, along with a number of their physical and chemical properties. There are two sections to this page: (1) View a cement, and (2) View a cement data file.

NOTE: Frequently you will see a small question mark icon, ? near a feature on page. This is a tool-tip icon; clicking on it will open a blue textbox that gives brief information about the feature in question.

\section{View a cement}

The top section of the page has (1) a pull-down menu to select the cement that you want to view, (2) a view of a false-color scanning electron microscope (SEM) image of the cement which has been color-coded to reveal the spatial distribution of the mineral phases, (3) an text box with additional information about the cement, and (4) a collection of quantitative data on the cement, under the heading "Cement data" that is initially collapsed and hidden when the page opens.

Selecting a different cement in the pull-down menu will update each of these fields to display the relevant data for that cement. The characterization techniques used to generate these data have been described in detail in previous publications [Bentz and Stutzman 1994, Bentz and Stutzman 1999].

\section{Segmented SEM image}

This section shows a single image field from a scanning electron micrograph that has been colored to indicate the locations of the various cementitious mineral phases in the cement powder. A key to the color mappings is provided with each image. 


\section{Information text box}

The text box immediately below the image displays information about the cement, including a brief description, the original source of the cementitious sample, the date when the cement was either received or analyzed, and the fineness measured either by the air permeability test (Blaine, ASTM C204 [ASTM 2008]) or by laser diffraction from a dilute suspension of cement powder particles in isopropyl alcohol.

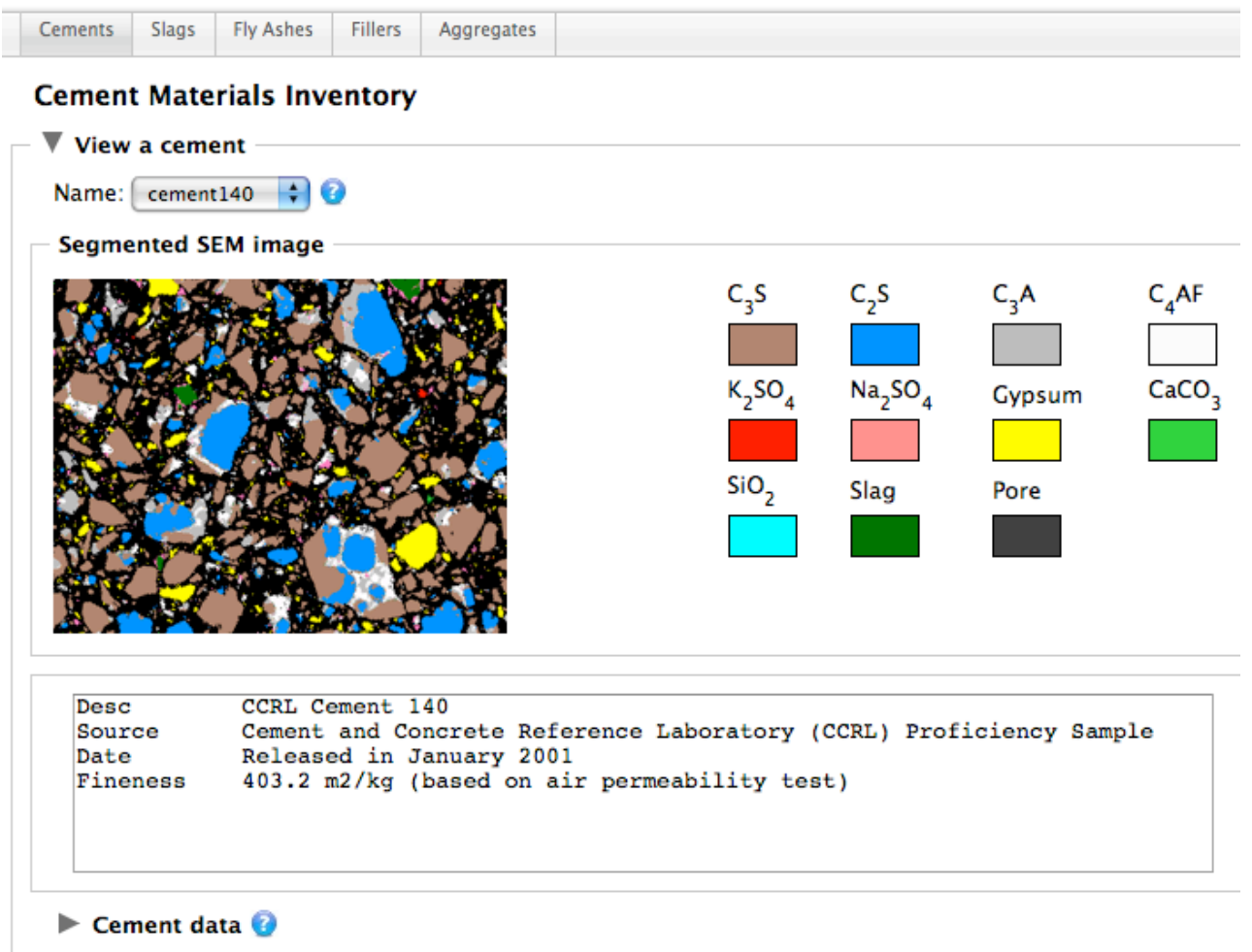

\section{Cement data}

This section is initially "collapsed" when the page opens. It can be displayed by clicking on the small grey triangle next to the "Cement data" subheading.

The fully displayed section contains a number of read-only text boxes and a couple of pull down menus that are described in the following list. 
PSD: This is a pull-down menu pointing to the file that contains the information on the particle size distribution (PSD) of the cement. In this educational version of VCCTL, selecting a different item on this menu has no effect on the cement. The only way to modify the PSD of a cement is to modify the file associated with the

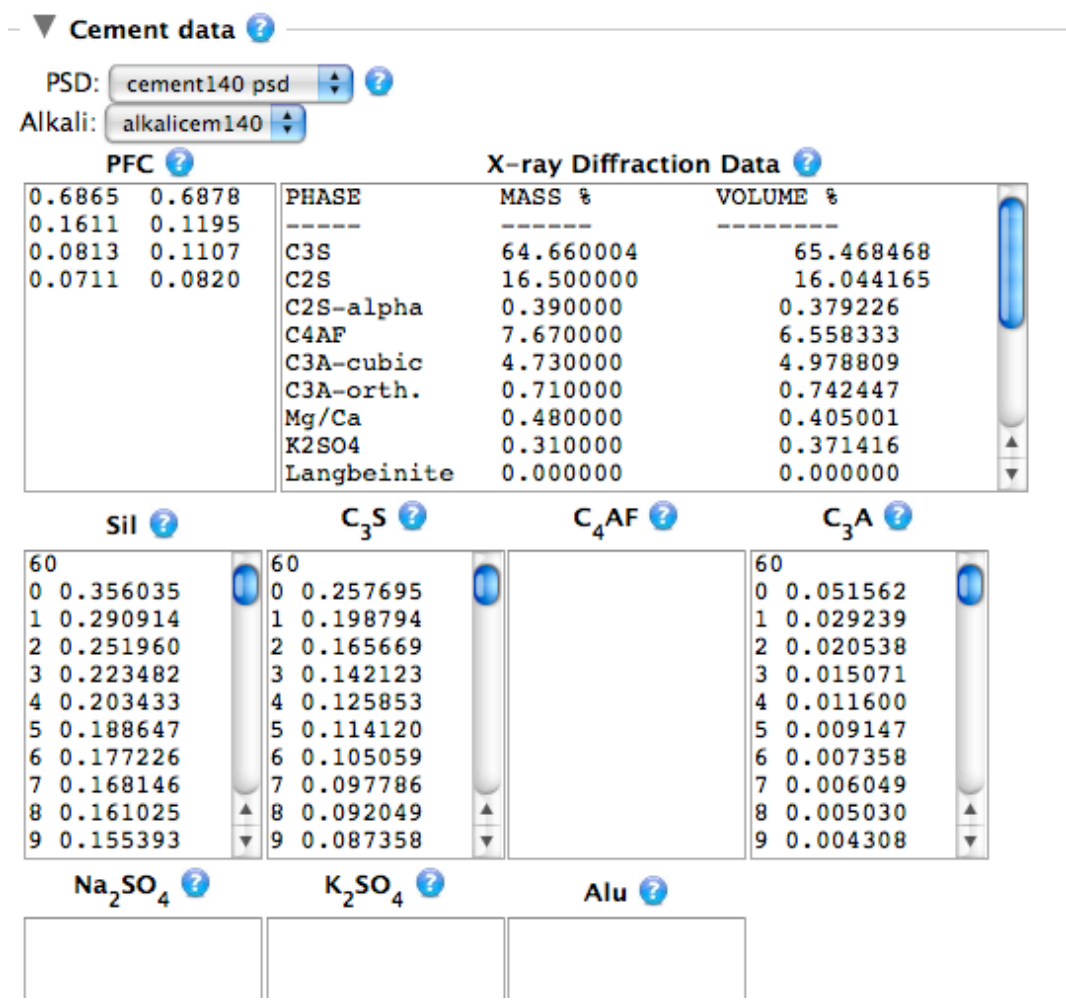

cement (e.g., cement140 psd as shown in the figure). Please refer to the next section, View a cement data file, for more information on how to modify the PSD of a cement.

Alkali: This is a pull-down menu pointing to the file that contains the information on the alkali content of the cement, including the total equivalent $\mathrm{K}_{2} \mathrm{O}$ and $\mathrm{Na}_{2} \mathrm{O}$ content as well as the readily-soluble fraction of each. In this educational version of VCCTL, selecting a different item on this menu has no effect on the cement. The only way to modify the alkali content of a cement is to modify the file associated with the cement (e.g., alkalicem 140 as shown in the figure). Please refer to the next section, View a cement data file, for more information on how to modify the alkali content of a cement.

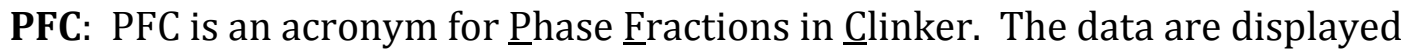
as either four or six rows of two columns each. The first row is for alite $\left(\mathrm{C}_{3} \mathrm{~S}^{2}\right)$, the

\footnotetext{
${ }^{2}$ Where it is convenient and unlikely to cause confusion, conventional cement chemistry notation is used in this guide. $\mathrm{C}=\mathrm{CaO}, \mathrm{S}=\mathrm{SiO}_{2}, \mathrm{~A}=\mathrm{Al}_{2} \mathrm{O}_{3}, \mathrm{~F}=\mathrm{Fe}_{2} \mathrm{O}_{3}, \mathrm{H}=\mathrm{H}_{2} \mathrm{O}$
} 
second row for belite $\left(\mathrm{C}_{2} \mathrm{~S}\right)$, the third row for tricalcium aluminate $\left(\mathrm{C}_{3} \mathrm{~A}\right)$, and the fourth row for tetracalcium aluminoferrite $\left(\mathrm{C}_{4} \mathrm{AF}\right)$. If a fifth and sixth row are present, they represent arcanite $\left(\mathrm{K}_{2} \mathrm{SO}_{4}\right)$ and thenardite $\left(\mathrm{Na}_{2} \mathrm{SO}_{4}\right)$, respectively. The left column indicates the volume fraction of the associated phase, on a total clinker volume basis, and the right column indicates the surface area fraction of the associated phase, on a total clinker surface area basis. The sum of each column should be 1.0 .

X-ray Diffraction Data: This field displays the results of a quantitative X-ray powder diffraction analysis of the cement using Rietveld refinement. The data are not used by the eVCCTL software, but are merely present to provide additional information to the user.

Sil, $\mathrm{C}_{3} \mathrm{~S}, \mathrm{C}_{4} \mathrm{AF}, \mathrm{C}_{3} \mathrm{~A}, \mathrm{Na}_{2} \mathrm{SO}_{4}, \mathrm{~K}_{2} \mathrm{SO}_{4}$, Alu: These fields display the kernels for the two-point correlation function calculated for the combined silicates, $\mathrm{C}_{3} \mathrm{~S}, \mathrm{C}_{4} \mathrm{AF}, \mathrm{C}_{3} \mathrm{~A}$, $\mathrm{Na}_{2} \mathrm{SO}_{4}, \mathrm{~K}_{2} \mathrm{SO}_{4}$, and combined aluminates, respectively. These data ares used to distribute the clinker phases among the cement particles that are created when a mix is requested. One or more of these fields may be blank.

In the educational version of VCCTL, none of these cement data may be permanently changed in the database. The text boxes are read-only and may not be modified. However, certain properties of a cement may be temporarily modified at the time when a mix is made (see Section 7.1 for more information).

\section{Mass fractions of sulfates}

Three calcium sulfate carriers are recognized in eVCCTL: gypsum (calcium sulfate dihydrate), bassanite (hemihydrate), and calcium sulfate anhydrite. This section shows the mass fractions of each of these carriers found in the cement, on a total solids basis. In eVCCTL, these values may not be permanently modified in the database. However, they may be temporarily changed at the time when a mix is made (see Section 7.1 for more information).

\section{View a cement data file}

This section is also collapsed when the page first opens. It can be displayed by clicking on the small grey triangle next to the heading "View a cement data file".

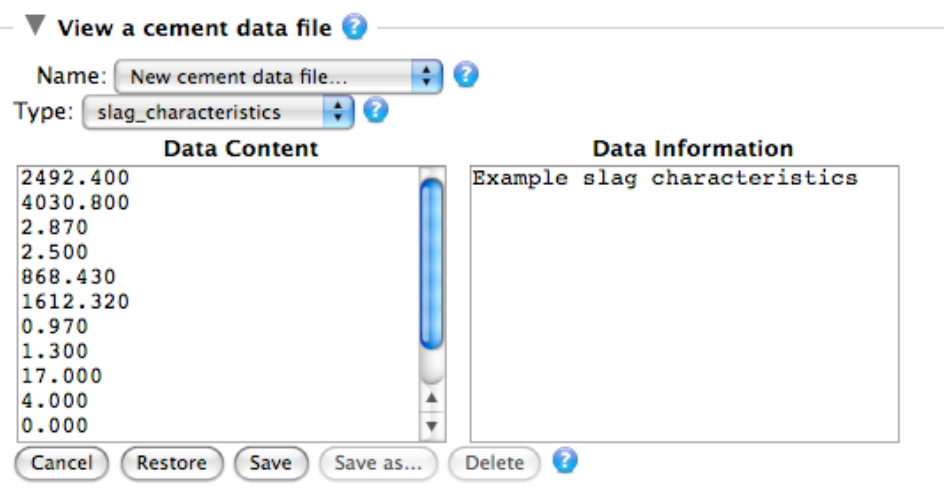


There are a number of different auxiliary data files that are used by eVCCTL to make mixes or simulate the hydration of materials, and this section enables the user to view and modify some of those data files. The left text box contains the actual data, and the right text box contains information on the formatting of the data file. Each type of data file is described in the following list:

psd: These files contain information on the particle size distribution of the cement powder. The left column is the equivalent spherical diameter in micrometers (i.e., the diameter of a sphere having the same volume as the irregularly shaped particle), and the right column is the volume fraction of particles having an equivalent spherical diameter between that row and the following row. Therefore, these data describe a discrete probability density function (PDF) for the particle sizes.

alkali_characteristics: These files contain information on the potassium and sodium content of the cement on a total solids basis. This data file has four or six rows. The first and second rows are the mass per cent equivalent total $\mathrm{Na}_{2} \mathrm{O}$ and $\mathrm{K}_{2} \mathrm{O}$, respectively. The third and fourth rows are the mass per cent readily soluble $\mathrm{Na}_{2} \mathrm{O}$ and $\mathrm{K}_{2} \mathrm{O}$, respectively. The fifth and sixth rows, if they are present, are the mass per cent $\mathrm{Na}_{2} \mathrm{O}$ and $\mathrm{K}_{2} \mathrm{O}$ added as $\mathrm{NaOH}$ and $\mathrm{KOH}$ to the mix water, respectively.

slag_characteristics: There is only one of this kind of data file in eVCCTL. It describes the physical and chemical properties of both the slag and the slag gel hydration product. This file can be modified but will have no effect on the calculations made by eVCCTL. More information on the meaning of each parameter is provided in Section 6.2 on Slags below.

parameter_file: There is only one of this kind of file in EVCCTL. It catalogs the values of several dozen empirical parameters that are used by the program that simulates hydration of cement pastes. The meaning of each parameter is beyond the scope of this guide.

chemical_shrinkage_file: In the full version of VCCTL, users can calibrate the time scale for hydration simulations using experimentally determined chemical shrinkage data. This file contains the measured data as an example, but this calibration feature is disabled in eVCCTL, so changing the file will have no effect on the calculations.

calorimetry_file: In the full version of VCCTL, users can calibrate the time scale for hydration simulations using experimentally determined isothermal calorimetry data. This file contains the measured data as an example, but this calibration feature is disabled in eVCCTL, so changing the file will have no effect on the calculations.

Users may alter any of the data files and save them by pressing the "Save" button below the text boxes. For example, if a user manually modifies the cement140 psd data file and saves the changes, the modified PSD data will be used any time that cement 140 cement is used to create a mix.

A copy of each original data file is stored in the database, so if a user wishes to return to the original data, the "Restore" button can be pressed, followed by the "Save" button. NOTE: The user must press the "Save" button after restoring original data or the previously modified data will remain. 


\subsection{Slags}

The slag material inventory page consists of a pull-down menu to select the slag to view (there is only one slag in the eVCCTL database), along with a textbox displaying the specific gravity of the slag and a second pull-down menu pointing to the file for particle size distribution. Again, in eVCCTL these fields cannot be modified or, in the case of the PSD file, can only be modified indirectly by changing the contents of the associated PSD file (e.g. cement141 psd) on the Cements page.

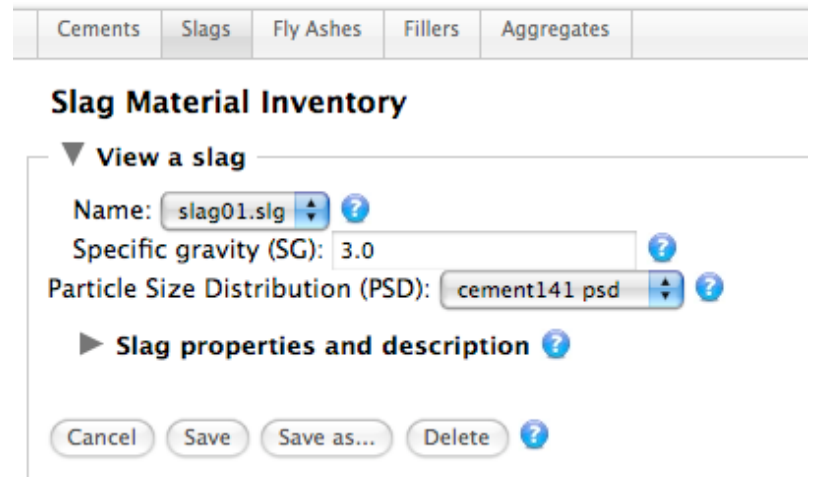

A second section, "Slag properties and description" is initially collapsed when the page opens, but can be expanded by clicking on the small grey triangle next to the heading. This section displays the chemical and physical properties that the eVCCTL hydration model needs to be able to simulate the hydration of the slag in a blended cement. The properties are self-explanatory, and the tool-tip can be used to gain further information on some of them. Notice that some of the properties relate to the slag itself, some relate to the slag "hydration product", and some must be specified for both the slag and the hydration product. In eVCCTL, these properties cannot be edited, but are displayed primarily for informational purposes.

\begin{tabular}{l|l|l|}
\begin{tabular}{l} 
V Slag properties and description \\
\multicolumn{1}{|c|}{ Property }
\end{tabular} & \multicolumn{1}{|c|}{ Slag } & Slag gel hydration product \\
\hline Molecular mass $(\mathrm{g} / \mathrm{mol})$ & 2492.4 & 4307.085 \\
Density $\left(\mathrm{g} / \mathrm{cm}^{3}\right)$ & 2.991 & 2.35 \\
Molar volume $\left(\mathrm{cm}^{3} / \mathrm{mol}\right)$ & 833.2998996990973 & 1832.8021276595744 \\
$\mathrm{Ca} /$ Si molar ratio & 0.97 & 1.25 \\
Si per mole of slag ? & 17.0 & \\
$\mathrm{H}_{2} \mathrm{O} /$ Si molar ratio & & 5.059 \\
$\mathrm{C}_{3} \mathrm{~A}$ per mole of slag ? & & 0.0 \\
Base slag reactivity ? & 1.0 & \\
\hline Description: ? & & \\
\hline
\end{tabular}




\subsection{Fly Ashes}

The fly ash material inventory page consists of a pull-down menu to select the fly ash to view (there is only one fly ash in the eVCCTL database), along with a textbox displaying the specific gravity of the fly ash and a second pull-down menu pointing to the file for particle size distribution. Again, in eVCCTL these fields cannot be modified or, in the case of the PSD file, can only be modified indirectly by changing the contents of the associated PSD file (e.g. cement141 psd) on the Cements page. Unlike slags, however, fly ash materials consist of multiple phases. Therefore, another field is displayed to indicate whether the phases are to be distributed on a particle basis (i.e. each fly ash particle is a single phase) or on a pixel basis (i.e. each particle contains multiple phases distributed randomly pixel by pixel). In eVCCTL, the fly ash in the database is set to distribute its phases on a particle basis. Although the user can click on the other radio button to choose the pixel-based distribution, this has no real effect because the ability to save the modified fly ash is disabled in this educational version.

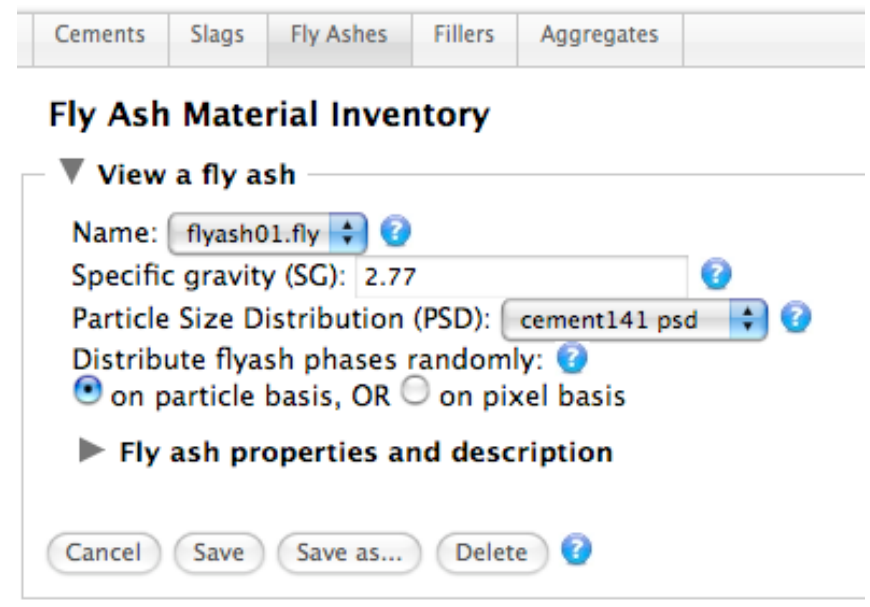

Like the slag inventory page, the fly ash page has a second section, initially collapsed when the page opens, for other fly ash properties. In this case, the fly ash properties are simply the volume fraction of the various phases comprising the fly ash. The seven eligible phases are shown in the accompanying figure. Again, the values in the table cannot be edited in eVCCTL but are displayed only for informational purposes. The phase distribution shown is similar to a fly ash that was characterized in 2004 at NIST [ Feng and Garboczi 2004]. 


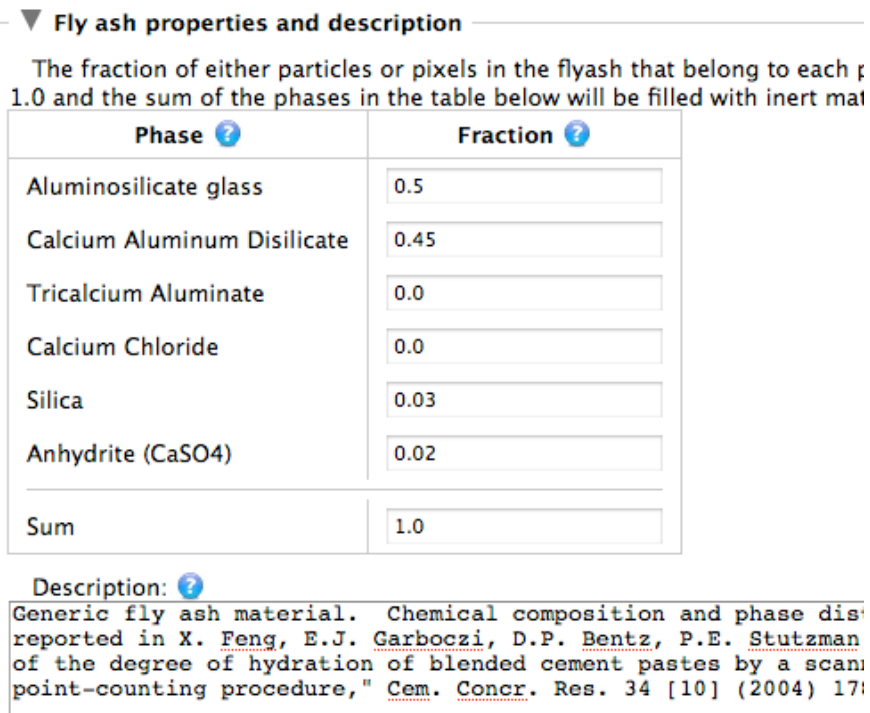

\subsection{Fillers}

Inert fillers have only two properties of interest: specific gravity and particle size distribution. The inventory of fillers in eVCCTL consists of three materials, (1) $\alpha$-quartz $\left(\mathrm{SiO}_{2}\right)$ with a specific gravity of 2.62, (2) corundum $\left(\mathrm{Al}_{2} \mathrm{O}_{3}\right)$ with a specific gravity of 4.05, and (3) periclase (MgO) with a specific gravity of 3.78. All three inert fillers have cement141 psd to describe their particle size distribution. In eVCCTL, these properties cannot be changed.

\begin{tabular}{l|l|l|l|l|} 
Cements & Slags & Fly Ashes & Fillers & Aggregates
\end{tabular}

\section{Filler Material Inventory}

\section{View inert fillers}

$$
\text { Name: periclase } \div ?
$$

Specific gravity: 3.78

Particle Size Distribution (PSD): cement141 psd $\$ ?$ Description:

Inert filler with density consistent with periclas Cement 141 from the CCRL proficiency sample progra

Cancel Save (Save as... Delete ?




\subsection{Aggregates}

Coarse and fine aggregates are included in the eVCCTL database for the purposes of creating mortar and concrete mixes. Three coarse aggregate sources and four fine aggregate sources have been characterized for particle shape, specific gravity, and linear elastic moduli. The shape characterization procedure involves capturing a 3D image of a packing of the aggregate particles, using X-ray computed tomography, and then analyzing the shape of individual particles by spherical harmonics. The procedure is described in [Garboczi 2002].

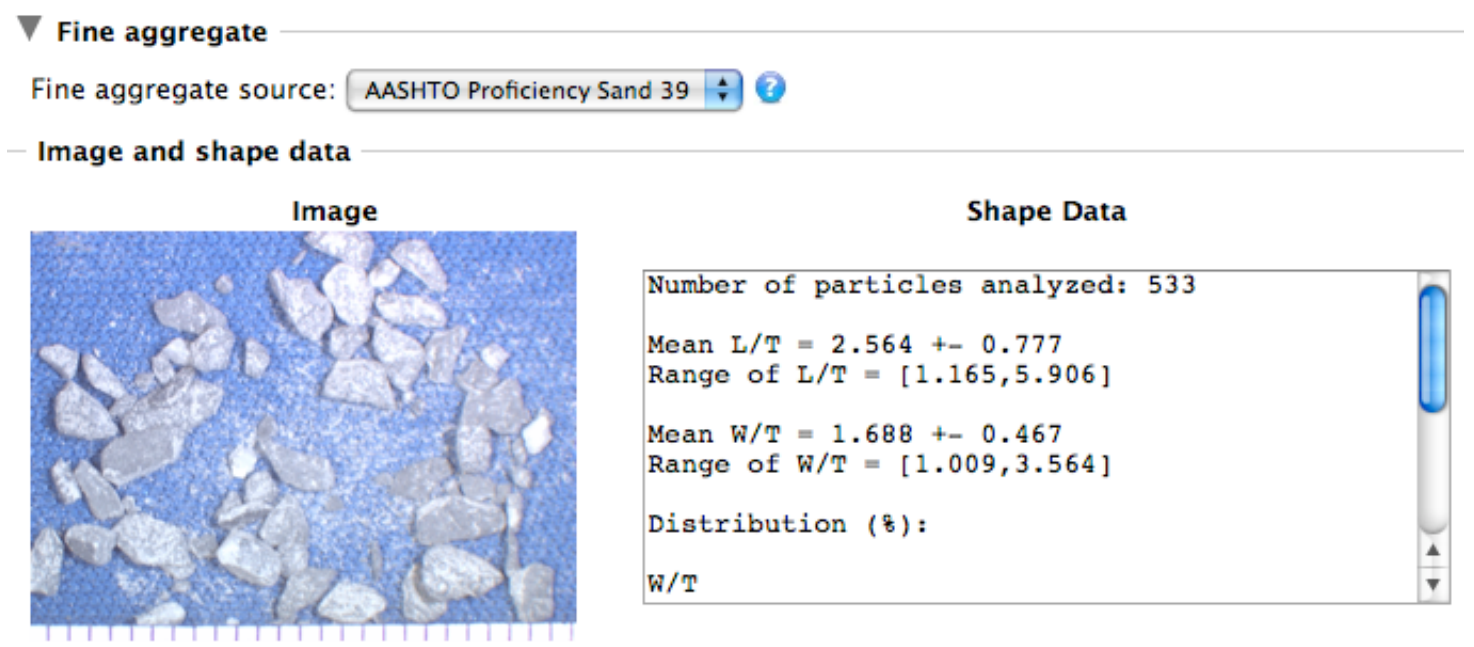

The aggregate materials inventory consists of one section for coarse aggregates and one for fine aggregates. Both sections are collapsed when the page first appears and can be opened by clicking on the small grey triangle next to the respective headings. Each section is identical except for the materials it displays, so the accompanying figures will illustrate the features for the fine aggregates only.

When the coarse or fine aggregate section is expanded, there is a pull-down menu to choose which aggregate source to examine. Below that is a section showing a color photograph of a small sample of the aggregate and an accompanying table that summarizes the gross shape data for the aggregate such as the distribution of ratios of length to width $(\mathrm{L} / \mathrm{W})$ and width to thickness $(\mathrm{W} / \mathrm{T})^{3}$. In the table, the mean and range of $\mathrm{L} / \mathrm{T}$ and $\mathrm{W} / \mathrm{T}$ are provided, and below that a table showing the distribution of particles with given $\mathrm{L} / \mathrm{T}$ and $\mathrm{W} / \mathrm{T}$. These data come from the spherical harmonic analysis, but it is useful to remember that the spherical

${ }^{3}$ In aggregate terminology, the length is the greatest linear dimension of an aggregate particle, the width is the greatest linear dimension in any direction perpendicular to the length axis, and the thickness is the greatest linear dimension the direction that is simultaneously perpendicular to both the length and the width. 
harmonic data in the database contain much more information about particle shape, enough to reproduce the 3D shape of a given particle of any size and rotational orientation in space.

Below the image and shape data, some physical properties of the aggregate are displayed, including the specific gravity, bulk modulus (in GPa) and shear modulus (in GPa). These fields cannot be edited by the user, but are displayed for informational purposes and so the user can see the values used for input in the calculations involving these materials. Finally, a text box displays other information about the aggregate, including a descriptive name, the source and intended use of the aggregate and, in some cases, the basic mineralogical content.

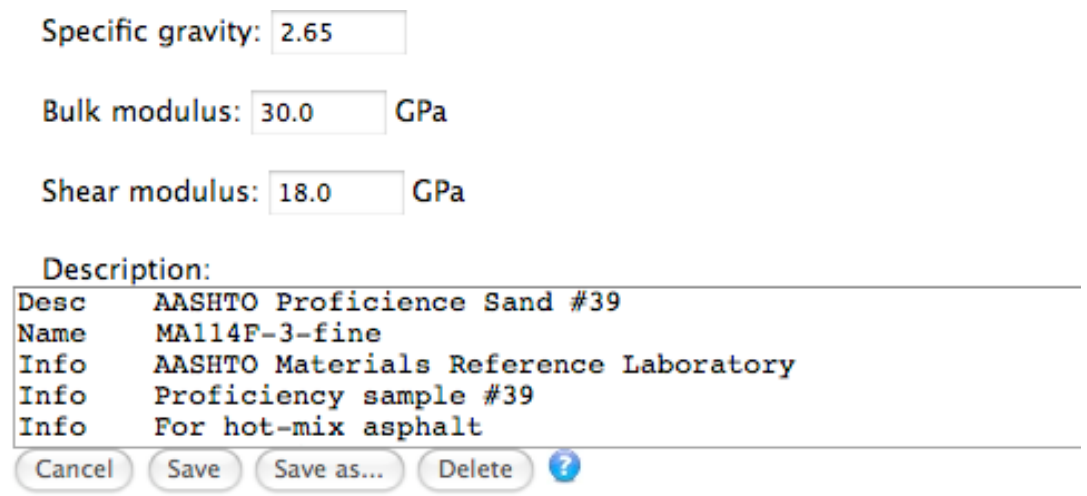

\section{Mix}

With some knowledge of the types of materials and their properties that are stored in the eVCCTL database, we turn now to the part of the software that enables one to create mixes and cure them. This part of the software is accessed through the "Mix" tab on the main menu bar, and has a submenu for accessing two pages, one for creating a mix and one for simulating its hydration.

A Note on the Operating Principles of VCCTL Programs: Before describing these parts of the software, it is useful to understand the underlying operating principles of the programs that create the mixes and simulate hydration. VCCTL software (both eVCCTL and the full VCCTL version) are based on a "digital image" approach to representing microstructure. In this approach, microstructures are mapped onto a regular 3D grid of cubic volume elements, often called pixels or voxels. For cement pastes, each voxel is $1 \mu \mathrm{m}$ on a side, but for larger scale packings of fine or coarse aggregates the voxel size depends on the smallest particle that will be placed. When a cement paste microstructure is created on this voxel grid, each voxel is occupied by exactly one "phase" (e.g., $\mathrm{C}_{3} \mathrm{~S}$, slag, saturated porosity, etc.). In this way, the programs that lie behind the VCCTL user interface are able to accurately reproduce microstructures that capture the desired phase assemblage, water/cement ratio, particle size and shape distribution, and surface areas. 
Simulating hydration of these initial microstructures involves rule-based interactions among the voxels in the microstructure. The rules are designed to mimic the various chemical reactions and mass transport that occur during hydration. As a result, the 3D digital image microstructure is incrementally changed to simulate microstructure development. This process introduces new hydration product phases such as $\mathrm{C}-\mathrm{S}-\mathrm{H}$ gel, $\mathrm{CH}$, ettringite, and several others.

The full details of the operating principles for the digital image approach can be found in other publications [Bentz 1997, Bentz 2005]. A discussion of computational tools that have been developed to analyze the properties of digital image microstructures can be found in [Garboczi and Bentz 1999]. Some of the artifacts and limitations of digital image approaches are described in [Garboczi and Bentz 2001].

\subsection{Prepare Mix}

This page is used to create an initial 3D cement microstructure consisting of particles of cement clinker, calcium sulfate carriers, and other selected compounds in water, as well as simulated packings of fine and coarse aggregates when the paste is acting as the binder in a mortar or concrete. There are three main steps involved in creating the mix: (1) specifying the solid cementitious binder properties, (2) specifying the mix proportions of the solid portion of the binder with water and aggregate, and (3) specifying the system size and other miscellaneous simulation parameters. Each of these steps is now described.

\section{Specifying the solid cementitious binder}

The principal component of the binder is one of the portland cements, which may be selected from among those in the database using the pull-down menu selector. Once the cement is selected, the volume fractions and surface area fractions of the clinker minerals may be modified for the mix if desired by expanding the section "Modify phase distribution of the clinker". The default values displayed in the tables are those stored in the database for the corresponding cement when it was characterized as already described. The table keeps a running sum of the two columns, which should both add to 1.0. If the user modifies the values in the columns in such a way that one or both columns do not sum to 1.0, the columns will be re-normalized to 1.0 when the mix is created.

The chosen cement also has default values for the mass fractions of the calcium sulfate carriers (dihydrate, hemihydrate, and anhydrite) which can be reviewed and modified by expanding the section headed "Modify calcium sulfate amounts in the cement". Remember that the displayed values are given on a total solid cement basis, and that all values are displayed as fractions, not percentages. 


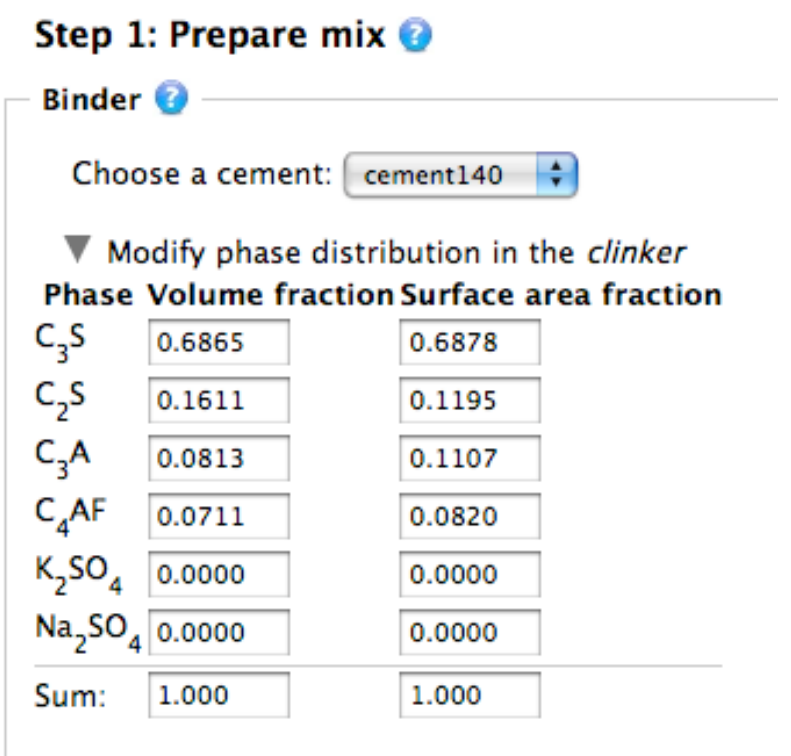

The last part of specifying the solid binder is to select the type and quantity of any supplementary cementitious materials (SCMs) or fillers. The categories for these materials are (1) fly ash, (2) slag, (3) inert filler, (4) silica fume, (4) limestone $\left(\mathrm{CaCO}_{3}\right)$, and (5) free lime (CaO). For fly ash, slag, and inert filler, the materials may be selected from the accompanying pull-down menu selector from those available in the database, as already described in Section 6. For silica fume, limestone, and free lime, the composition and specific gravity are assumed fixed, and the user is asked only to specify the particle size distribution by selecting the file for the PSD from one of those in the database. Recall that the PSDs associated with each file can be viewed on the Lab Materials page as described in Section 6.1. Once the material and characteristics are selected, the user may specify either the mass fraction or volume fraction that the material will occupy on a total solid binder basis. This is equivalent to specifying a replacement level for each component. Note that the total fraction of cement in the binder is reduced as the fractions of these other materials is increased. Note, if the mass fraction is specified, then the volume fraction will be automatically calculated and displayed based on the specific gravities of all the components. Similarly, specifying the volume fraction will cause the mass fraction to be automatically calculated and displayed.

\section{Specifying the mix proportions}

When the solid portion of the binder is specified, the next section can be used to specify the water/binder mass ratio $(\mathrm{w} / \mathrm{b})$ using the pull-down menu selector. The options for the $\mathrm{w} / \mathrm{b}$ value cover the range normally used for concrete and also include the value 0.485 , the latter which is used for ASTM C109 mortar cube compressive strength specimens [ASTM 2008]. Read-only text fields for viewing the 
mass fractions and volume fractions of solid binder and water corresponding to the selected $\mathrm{w} / \mathrm{b}$ ratio.

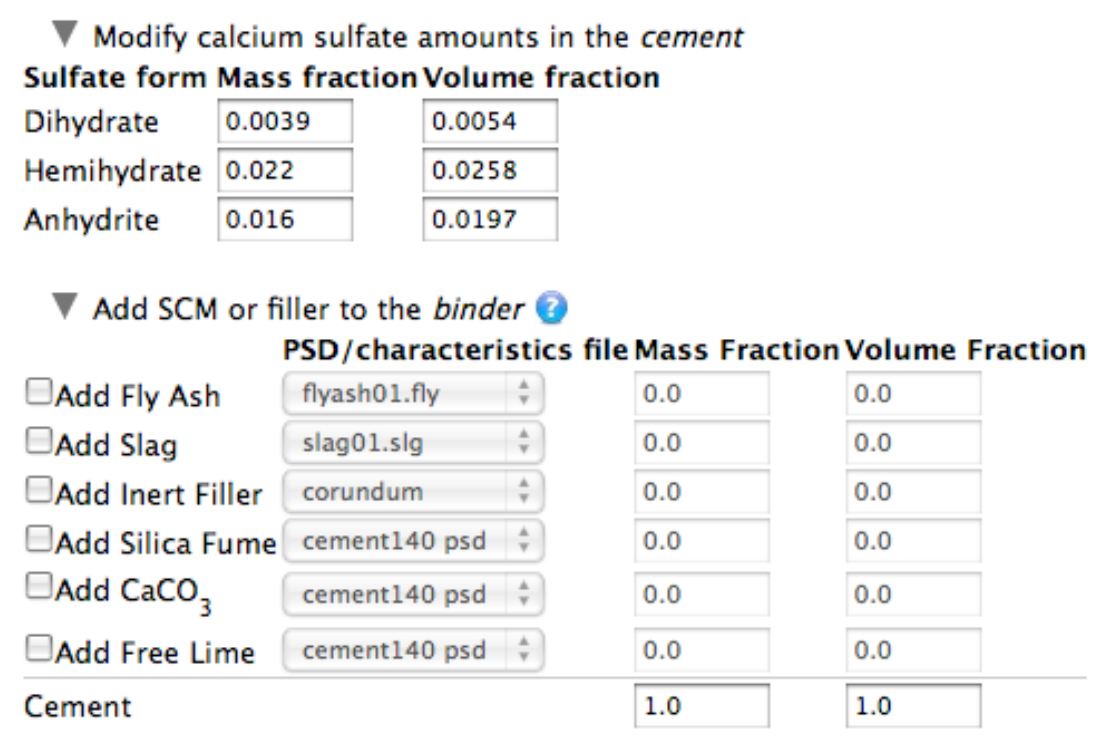

This section also includes the option to add coarse or fine aggregate to the mix to create a mortar or concrete. To add aggregate, click on the checkbox next to the coarse or fine aggregate. When this is done, the text boxes for the mass fraction and volume fraction, initially disables, become enabled and the user can type in the desired mass fraction or volume fraction, on a total mortar or concrete basis.

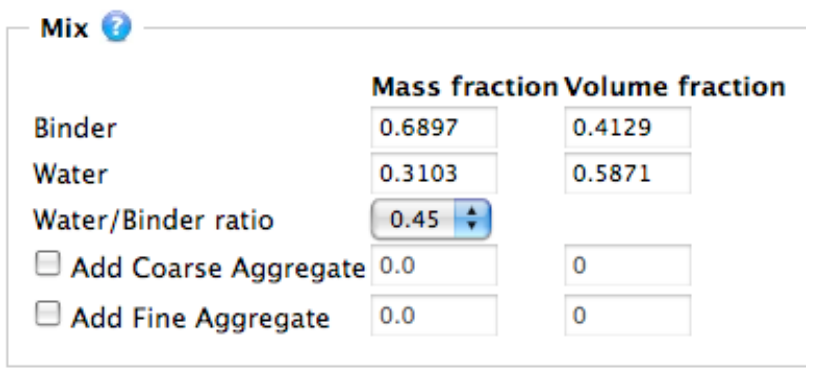

In addition, when one of the aggregate checkboxes is selected, a new section appears below it, intially collapsed, called "Change properties". Expanding this section enables the user to specify the aggregate source, specific gravity, and grading (or size distribution). 
Prepare Mix

\begin{tabular}{|c|c|c|c|}
\hline \multirow{2}{*}{\multicolumn{2}{|c|}{$\checkmark$ Add Fine Aggregate }} & & \multirow[b]{2}{*}{0.5694} \\
\hline & & 0.65 & \\
\hline \multicolumn{4}{|c|}{$\nabla$ Change properties } \\
\hline \multicolumn{4}{|c|}{ Aggregate source: AASHTO Proficiency Sand $39 \div$} \\
\hline \multicolumn{4}{|c|}{ Specific gravity: 2.65} \\
\hline \multicolumn{4}{|c|}{ Grading: ASTM-C109.gdg } \\
\hline Sieve & Diameter (mm) & Fraction & etained \\
\hline No. 5 & $4.000-4.5$ & 0.0 & \\
\hline No. 6 & $3.350-4.000$ & 0.0 & \\
\hline No. 7 & $2.800-3.350$ & 0.0 & \\
\hline No. 8 & $2.360-2.800$ & 0.0 & \\
\hline No. 10 & $2.000-2.360$ & 0.0 & \\
\hline No. 12 & $1.700-2.000$ & 0.0 & \\
\hline No. 14 & $1.400-1.700$ & 0.0 & \\
\hline No. 16 & $1.180-1.400$ & 0.0 & \\
\hline No. 18 & $1.000-1.180$ & 0.0 & \\
\hline No. 20 & $0.850-1.000$ & 0.0 & \\
\hline No. 25 & $0.710-0.850$ & 0.02 & \\
\hline No. 30 & $0.600-0.710$ & 0.0 & \\
\hline No. 35 & $0.500-0.600$ & 0.28 & \\
\hline No. 40 & $0.425-0.500$ & 0.0 & \\
\hline No. 45 & $0.355-0.425$ & 0.45 & \\
\hline No. 50 & $0.300-0.355$ & 0.0 & \\
\hline
\end{tabular}

Notice that changing the specific gravity of the aggregate causes the volume fractions of the aggregate, binder, and water all to change in response. Finally, aggregate grading is displayed in tabular form using the customary sieve designations to indicate the size bins that are used. The user may specify the grading by typing in the mass fraction of aggregate retained in each sieve. The sum of the mass fractions in the table should be 1.0, but it will be normalized to 1.0 if not. eVCCTL comes with one pre-selected fine aggregate grading that corresponds to the

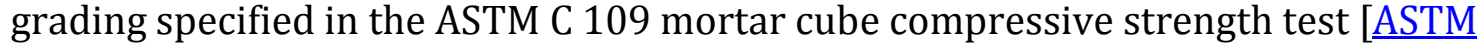
2008]. The coarse aggregate section also comes with a default aggregate grading, but the default grading does not correspond to any particular test.

Note: In the full version of VCCTL, the aggregate grading specified manually by the user can be saved in the database for easy retrieval in subsequent mixes, but in eVCCTL this feature has been disabled.

\section{Specifying simulation parameters}

After the mix proportions are specified, the user may optionally select or modify any of several simulation parameters, each of which is now described.

Random number generator seed: When the virtual microstructures are created, random numbers are used to randomly select the positions of particles as they are added, to stochastically distribute the clinker phases within the constraints 
of the two-point correlation functions, and a variety of other tasks. The random number generator used in the VCCTL programs require an initial "seed" value, which must be a negative integer. Under ordinary circumstances, the seed value will be chosen automatically, but the user may also specify a particular seed value, if desired, by checking the box and typing a negative integer in the text box. If a nonnegative integer number is typed in the box, it will be ignored.

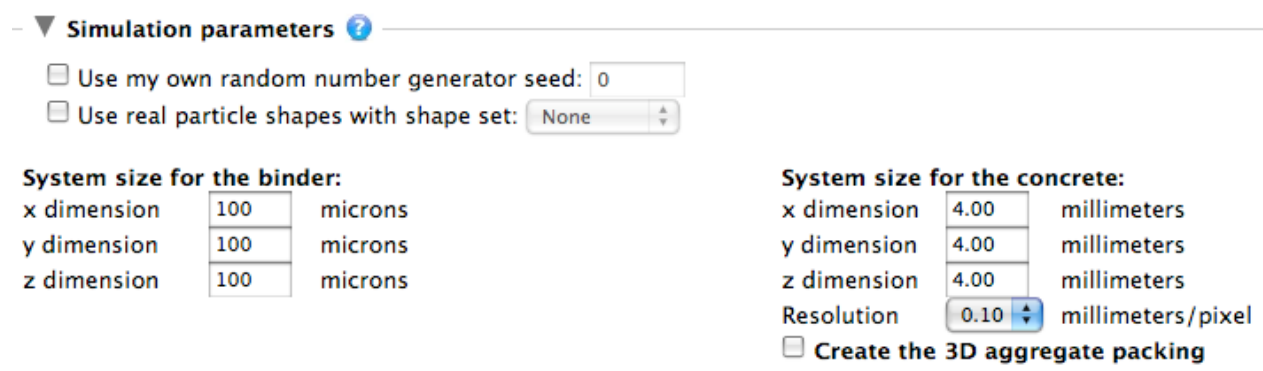

Real particle shapes: Check this box if you want the cement particles in the microstructure to have realistic shapes. As already described, the 3D shapes of aggregate particles have been characterized by spherical harmonic analysis and stored in the VCCTL database to recreate realistic aggregate packings. A nearly identical procedure has been used to characterize the particle shapes of several different portland cement powders, except that X-ray microtomography is required to obtain sufficient spatial resolution to characterize the particles using spherical harmonics [Garboczi and Bullard 2004]. To obtain realistic cement particle shapes in the microstructure, mark the check box and select the shape set from the pulldown menu selector. Note that requesting realistic particle shapes will require significantly more time to create the microstructure, sometimes two or three times as long.

Note: If the real particle shape checkbox is not selected, then the cement particles all will be digitized spheres.

System size for the binder: The number of voxels in each linear dimension of the 3D grid can be chosen by the user, the default value being 100 in each direction. As already mentioned, each cubic voxel in the cement paste is $1 \mu \mathrm{m}$ on a side, so the number of voxels in each dimension is numerically equal to the linear dimension. Note that larger values of the linear dimensions will require significantly more time to create the microstructure; the time required to create a microstructure scales linearly with the number of voxels $N_{c p}$ in the grid, which can be calculated according to the equation

$$
\mathrm{N}_{\mathrm{cp}}=\mathrm{N}_{\mathrm{x}} \times \mathrm{N}_{\mathrm{y}} \times \mathrm{N}_{\mathrm{z}}
$$

where $N_{x}, N_{y}$, and $N_{z}$ are the numbers of voxels in the cement paste in the $x, y$, and $\mathrm{z}$ directions of the grid.

System size for the concrete: This section appears only if fine or coarse aggregate is being added to create a mortar or concrete. The default values for the 
linear dimensions and resolution are determined by the grading specified by the user. However, these values may be changed subject to the following constraints:

The minimum linear dimension of the concrete system must be at least twice as big as the opening of the coarsest sieve that retains any aggregate.

The resolution chosen from the pull-down menu selector must be no more than half the opening of the finest sieve that retains any aggregate.

These constraints are used to ensure that each aggregate particle in the grading fits into the box and can be approximately visualized in the packing. If either of these constraints is violated, an alert box will appear with a message describing which constraint was violated. Clicking the "OK" button on the dialog box dismisses it and also causes the offending dimension or resolution to be reset to an acceptable value that satisfies the constraints.

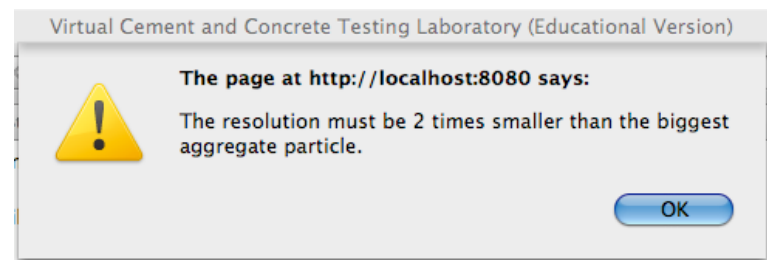

Note: Even when coarse or fine aggregates are included in the mix, the 3D aggregate packing is not created by default. To override this behavior and force the aggregate packing to be created, the checkbox next to "Create the 3D aggregate packing" must be checked.

Note: Creating a virtual aggregate packing often takes significant computational resources because the shapes are created individually from the spherical harmonic coefficients stored in the database. As with the cement paste system, the time required to create a 3D aggregate packing will scale linearly with the number of voxels $N_{a p}$ in the aggregate packing, which can be calculated according to the equation:

$$
N_{a p}=\frac{L_{x} \times L_{y} \times L_{z}}{\lambda^{3}}
$$

where $L_{x}, L_{y}$, and $L_{z}$ are the linear dimensions of the grid in $\mathrm{mm}$, and $\lambda$ is the resolution in $\mathrm{mm} /$ voxel.

Note: If fine or coarse aggregates are included in the mix, then a flat "slab" of aggregate will be inserted parallel to the yz plane in the center of the cement paste microstructure, regardless of whether or not an aggregate packing is requested. This aggregate slab is inserted to simulate the packing limitations of cement particles near an aggregate surface, the phenomena leading to the interfacial transition zone (ITZ) in mortar and concrete. The properties of the ITZ are important in determining the mechanical properties and transport properties of mortar and concrete [Bentz and Garboczi 1999b], so it is important that the ITZ be recreated in the virtual cement paste microstructure so that its properties can be subsequently computed and incorporated into calculations of mortar and concrete properties. 


\section{Saving the mix}

The last steps in creating a mix are to give the mix a unique name (i.e. one that does not already exist in the database) and execute the mix creation program. Type a name for the mix in the text box provided. Names can include upper case or lower case letters, numbers, or spaces. After typing the proposed name and clicking anywhere outside the text box, the software will validate the name. A green checkmark next to the name indicates that it is valid.

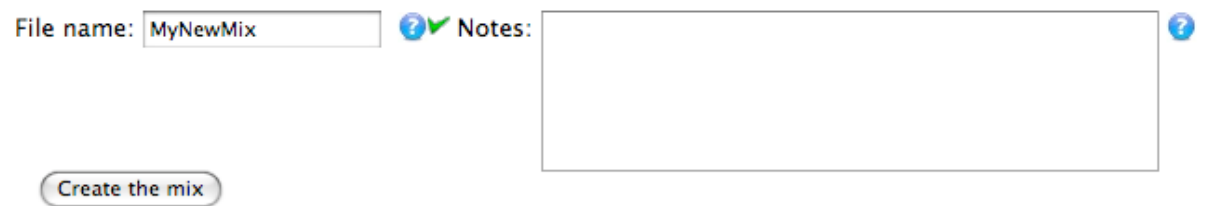

On the other hand, a red $\mathrm{X}$ indicates that the name has already been used for an existing mix.

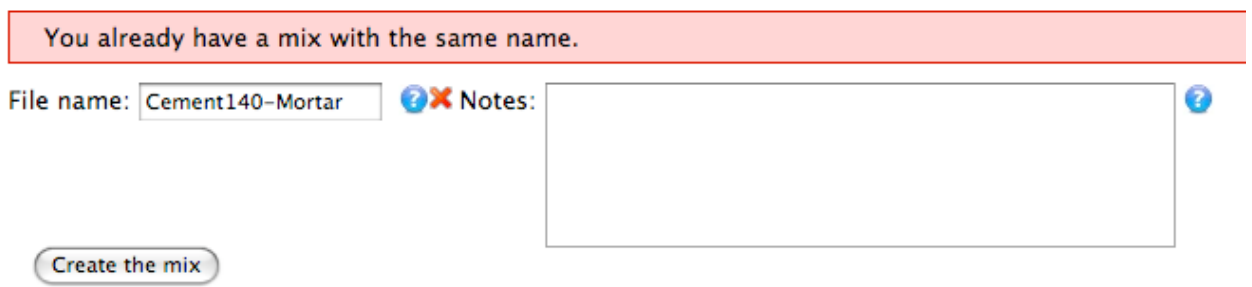

Once a valid name has been chosen, click on the "Create the mix" button to begin creating the mix. The status of the mix operation can be checked on the "My Operations" page, as described in detail in $\underline{\text { Section } 9}$. 


\subsection{Hydrate Mix}

The NIST cement hydration model [Bentz 1997, Bentz 2005] operates directly on 3D digital images of cement paste microstructures created as described earlier. Execution of the model requires a starting microstructure, information about the curing conditions (thermal conditions and moisture state), and the frequency at which to output various data for later analysis.

To begin hydrating a mix, first select the mix name from the pull-down menu selector. This is the name chosen when the mix was created. In addition, at this point you may specify the apparent activation energies of the three major "net" hydration processes that can occur: (1) cement hydration, (2) pozzolanic reactions,

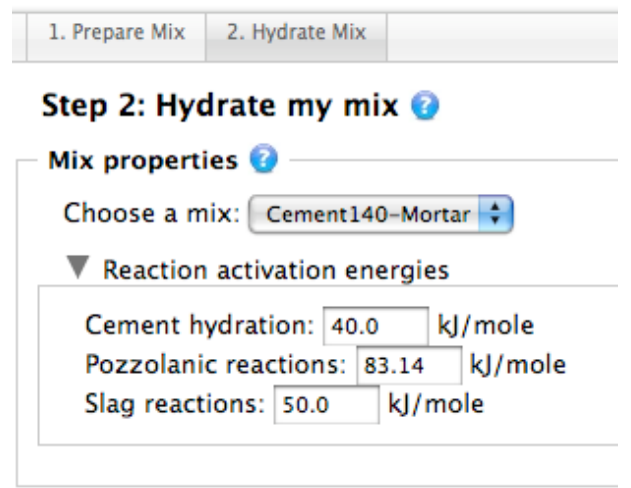

including fly ash hydration and silica fume reactions and (3) slag hydration. The default values that are provided reflect sensible values based on a survey of the literature (for example, see ASTM C 1074 [ASTM 2008]). The section for modifying the activation energies is collapsed when the page first opens, but may be expanded by clicking on the small grey triangle next to the heading "Reaction activation energies".

\section{Thermal conditions}

The thermal condition of the hydrating material may be (1) isothermal, (2) semi-adiabatic, or (3) adiabatic.

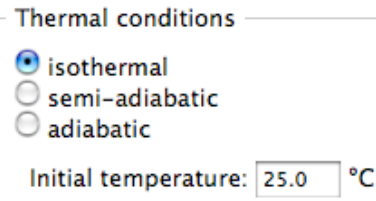


Isothermal: The material is in diathermal contact with a constant-temperature reservoir and heat transfer is sufficiently rapid to maintain the material at the temperature of the reservoir. The default value is $25^{\circ} \mathrm{C}$.

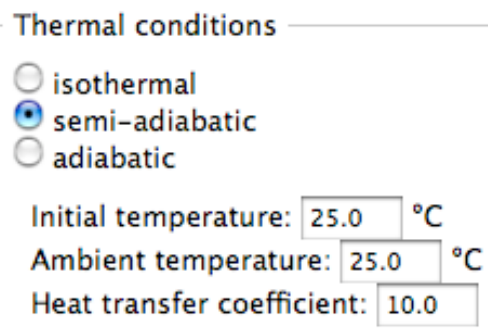

Semi-adiabatic: Heat generated by hydration reactions is transferred to a surrounding reservoir that is at a fixed temperature, but the transfer rate is slow enough that some of the generated heat causes the material temperature to increase. If this option is selected, then not only the initial temperature of the material must be specified (default $25^{\circ} \mathrm{C}$ ), but also the temperature of the surrounding reservoir (default $25^{\circ} \mathrm{C}$ ) and the effective heat transfer coefficient, in units of $\mathrm{W} / \mathrm{K}$ (default 10.0).

Adiabatic: The material is perfectly insulated from its environment, so all the heat generated by hydration reactions is used to increase the temperature of the material. If this option is chosen, only the initial temperature of the material must be specified. The default value is again $25^{\circ} \mathrm{C}$.

\section{Aging}

This section is used to specify the total length of time that the material should be hydrated. The time is specified by entering the desired number of days in the text box provided or, alternatively, by specifying a maximum degree of hydration at which the simulation will terminate.

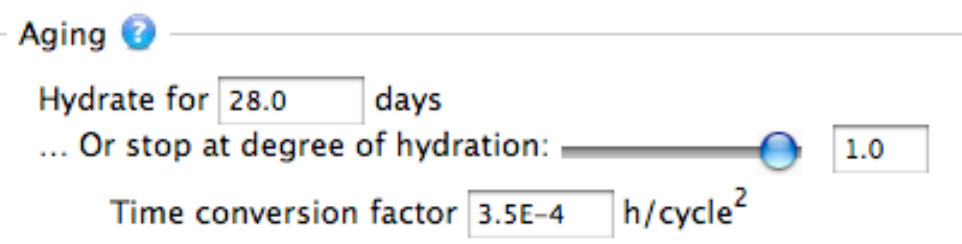

The other required element is the "time conversion factor", which has units of $\mathrm{h} /$ cycle $^{2}$. The NIST hydration model proceeds in repeated "cycles" of dissolution, diffusion, and reaction. These cycles have no intrinsic time scale, so one must define an assumed relationship between time (in hours) and computational cycles. In the current version of eVCCTL, hydration time, $t$, in hours is related to the number of computational cycles, $\mathrm{n}$, according to the parabolic relation 


$$
\mathrm{t}=\beta \mathrm{n}^{2}
$$

where $\beta$ is a time conversion factor that must be specified. The default value of $3.5 \times$ $10^{-4}$ is a value that works reasonably well for a number of cements, but which is not optimized to any particular cement. To optimize the time conversion parameter, $\mathrm{a}$ calibration of the model against some experimental measure of the degree of hydration, chemical shrinkage, or isothermal heat release should be made.

Note: The parabolic relation employed for the time scale is not used for any fundamental reason, but only because it often provides a reasonable fit to experimental measurements of the progress of hydration with time, provided that the time conversion factor is calibrated sufficiently well.

\section{Saturation conditions}

The two moisture condition options are saturated or sealed. The saturated condition means that the cement paste is in contact with a reservoir of excess water. As free water in the capillary pores is consumed by the hydration reactions, it is immediately replaced by water from the reservoir. Note, however, that once the capillary porosity reaches its percolation threshold and becomes disconnected,

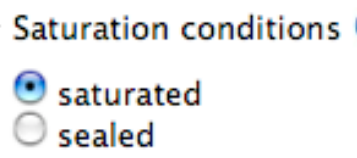

water replacement is no longer possible even under saturated conditions. The sealed condition means that free water consumed during hydration is not replaced. Instead, the capillary pores are progressively emptied of water, starting in those pore regions with the largest effective diameters.

\section{Simulation parameters}

This section is collapsed when the page first opens because it will not usually be of interest. It can be expanded by clicking on the small grey triangle next to the heading. The only simulation parameter that can be modified in eVCCTL is the value of the seed for the random number generator. See the discussion on random

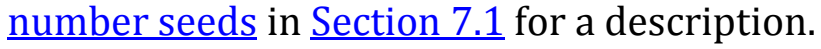

\section{Data output}

This section is collapsed when the page first opens. It can be expanded by clicking on the small grey triangle next to the heading. This section can be used to specify how frequently (in hours of simulated age) the hydration model will output certain properties to data files.

Evaluate percolation of porosity ... Percolation properties like this one tend to consume significant computational time to calculate because the calculations 
involve nested iterations over most or all of the system voxels. Therefore, it is recommended that percolation properties not be evaluated any more often than necessary. The percolation state of the capillary porosity determines the point at which water can no longer be absorbed from an external source to maintain saturated conditions. Once the hydration model detects that the pore space is depercolated, this calculation will no longer be made no matter what value is typed into the text box. The default value is $1.0 \mathrm{~h}$.

Evaluate percolation of total solids ... This property provides an indication of initial setting time, so it should be evaluated fairly frequently to obtain a reasonable assessment of setting time of a material. The default value is $0.5 \mathrm{~h}$.

Output hydrating microstructure ... The state of the entire 3D microstructure can be saved at regular intervals during the hydration process. Subsequent calculations of the linear elastic moduli, compressive strength, and transport properties of the material at a particular state of hydration can only be made if the microstructure is available at that state. The default value is $72.0 \mathrm{~h}$.

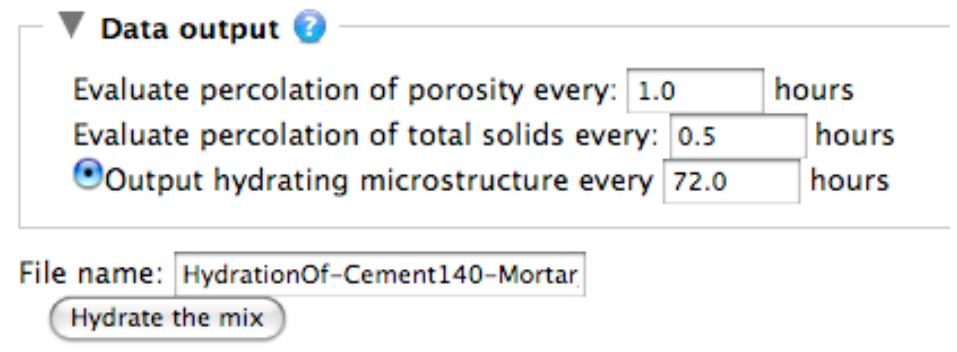

\section{Executing the hydration simulation}

To execute the simulated hydration operation, provide a unique name for the operation in the box next to "File name" at the bottom of the page. The default name is the name of the mix with the prefix "HydrationOf-" prepended. The default name can be modified, but must be unique. The software validates the name before and will indicate a green $\checkmark$ (okay) or a red $\mathrm{c}$ (invalid) next to the name. Once a valid name is selected, click on the "Hydrate the mix" button to launch the operation. The status of the hydration operation can be checked on the "My Operations" page, as described in detail in Section 9.

Note: One or more hydration operations for a particular mix can be requested and launched even before the mix operation has been completed. If the mix operation is still running when the hydration request is made, a message will appear saying,

"The mix you want to hydrate is not ready now. The hydration will begin as soon as the mix preparation is finished".

In other words, the hydration operation is queued to run as soon as the mix operation completes and a starting microstructure is available. 


\section{Measurements}

In eVCCTL, there are 61 properties that are continuously tracked during a hydration operation, and all of them are stored in a data file that can be accessed for online plotting or exporting to a spreadsheet for further analysis. See Appendix II for a listing of all the available "hydrated properties". In addition, the linear elastic moduli, compressive strength and transport properties of cement pastes, mortars, or concretes can be calculated on hydrated microstructures. The Measurements page provides access to all these virtual measurement capabilities.

Clicking on the "Measurements" tab of the main menu bar opens a page with a submenu having two options: (1) Plot Hydrated Properties, and (2) Measure Cement/Concrete Properties.

\subsection{Plot Hydrated Properties}

This page provides a flexible inline plotting capability for plotting the evolving properties of a hydrating material. To create a plot, first select the desired $\mathrm{x}$-axis property from the pull-down menu selector. The default x-axis is "Time", in hours,but any other hydrated property can be selected as well.

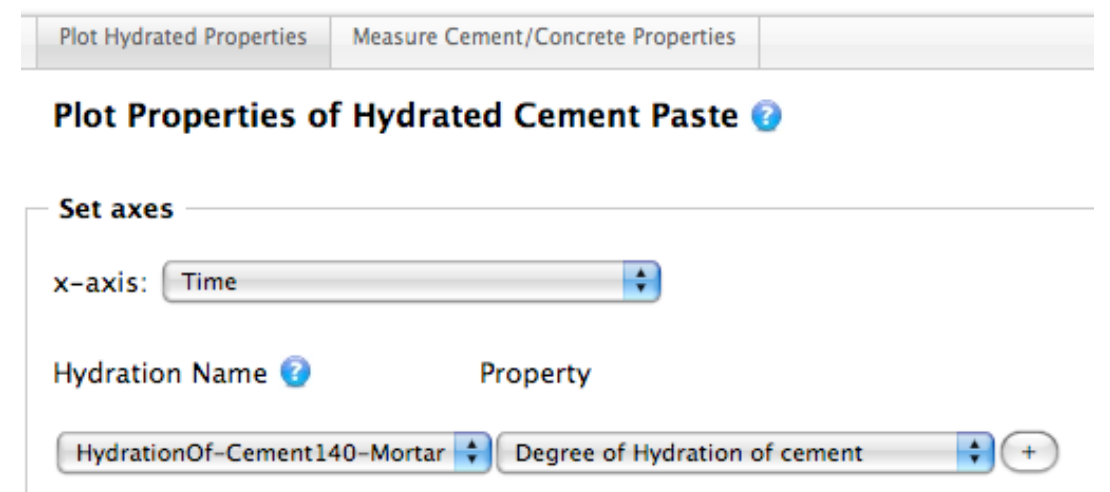

With the $\mathrm{x}$-axis selected any number of properties can be simultaneously plotted on the y-axis, including multiple properties from a single hydration simulation, or a comparison of the same properties for different hydration simulations. To create a plot, first select a hydration operation on the left pull-down menu selector (under the heading "Hydration Name"), and then select the desired property to plot in the right pull-down menu selector (under the heading "Property"). Doing so will immediately create the xy plot in the "Plot result" section. 


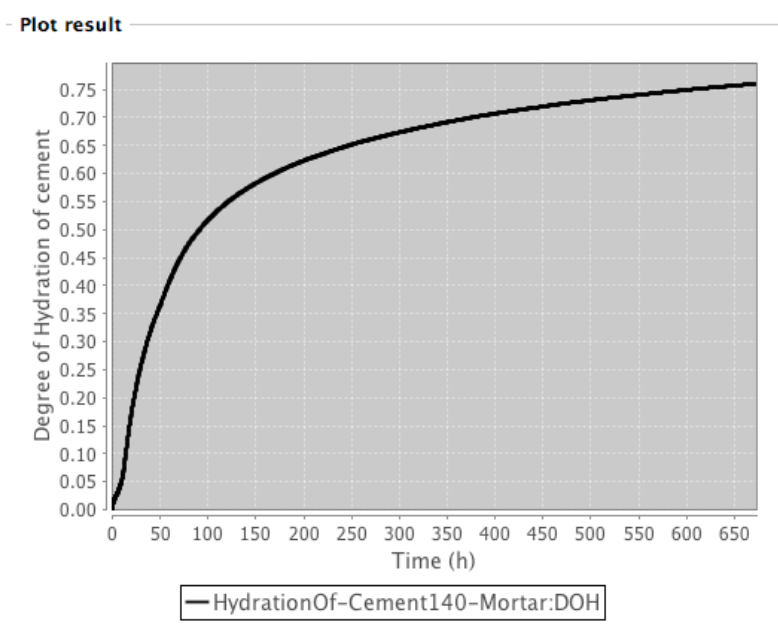

The plot is accompanied by a legend indicating both the hydration operation and the property, separated by a colon.

Click the "+" button next to the first property in the "Set axes" section to plot a second property on the same plot. This will create a second row with the same pull down menus repeated. The example shown below plots both the degree of hydration and total capillary porosity against time for the same hydration operation. Notice that the legend is updated to display the information for each curve in the plot.

Note: When plotting multiple properties on the same graph, the properties must all have commensurate units. For example, both the degree of hydration and the total porosity are dimensionless quantities, so they can be plotted together. However, the degree of hydration and isothermal heat release have different units, so they cannot be plotted simultaneously. The pull-down menu selectors automatically exclude incommensurate properties.

You can also compare properties from different hydration operations to analyze differences in the behavior of the two systems. The following example adds to the example just given by plotting the degree of hydration for another hydration operation. Notice that the second hydration operation, "HydrationOf-ASTMC10902 " only ran for 24 hours.

Plotted curves can also be removed from the graph by clicking on the "-" button next to the corresponding row in the "Set axes" section.

Note: Under some conditions, the generated plot may not automatically rescale its axes in an optimal way. This can be corrected by simply clicking once anywhere within the region of the plot itself.

It is also possible to zoom in on a narrow range of the x-axis. To do so, place the mouse within the plot field at the beginning $x$ value. Hold the mouse button down and drag to the ending $x$ value. Releasing the mouse will automatically generate the rescaled plot. Again, to go back to the optimal scaling needed to show all the data, just click once within the plot region. 


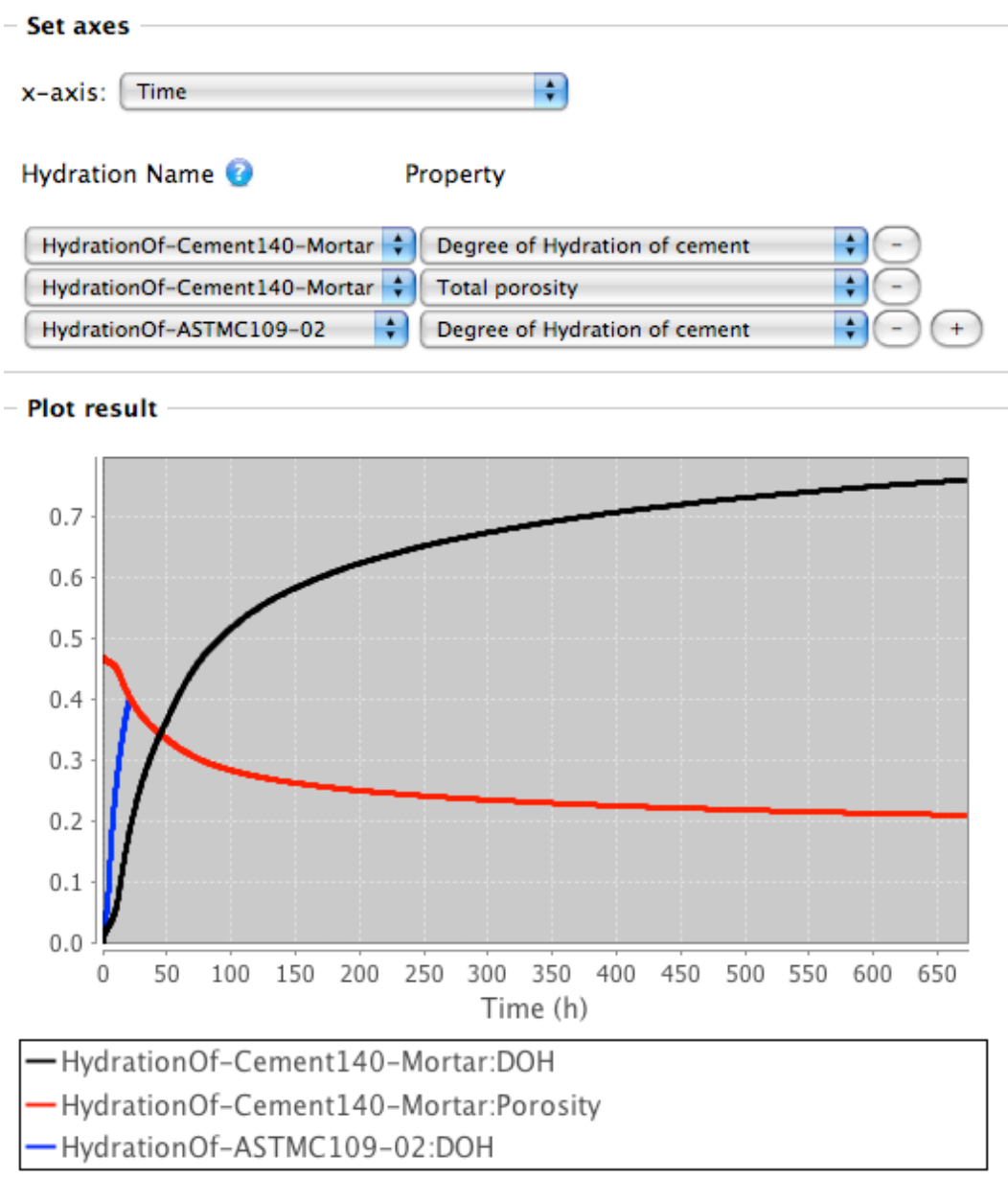

Finally, a high-resolution plot can be created in separate pop-up window by clicking on the "High resolution version" link below the legend. The same zooming features apply to the high-resolution plot as for the regular plot.

Note: When a hydration operation is running, its progress can be monitored by going to this plotting page. The default plot, which has time on the x-axis, will show how much simulation time has been reached, even if the operation has not completed.

\subsection{Measure Cement/Concrete Properties}

Clicking on this subtab opens a page for calculating the linear elastic properties, compressive strength, and the effective diffusivity of cement pastes, mortars, or concretes that have been hydrated. The desired hydration operation can be chosen from the pull-down menu selector. When this is done, a listing of the available hydration times for this operation appears under the heading "Properties".

Recall that, when a hydration operation is requested, you have the option to select the time intervals at which to output the partially hydrated 3D microstructures. For example, if you chose $72.0 \mathrm{~h}$ for this interval, then 
microstructures were saved at approximately $72 \mathrm{~h}, 144 \mathrm{~h}, 216 \mathrm{~h}$, etc. These are the same times that now appear in the list on this page, as individually collapsed sections, any of which can be expanded by clicking on the small grey triangles next to the headings.

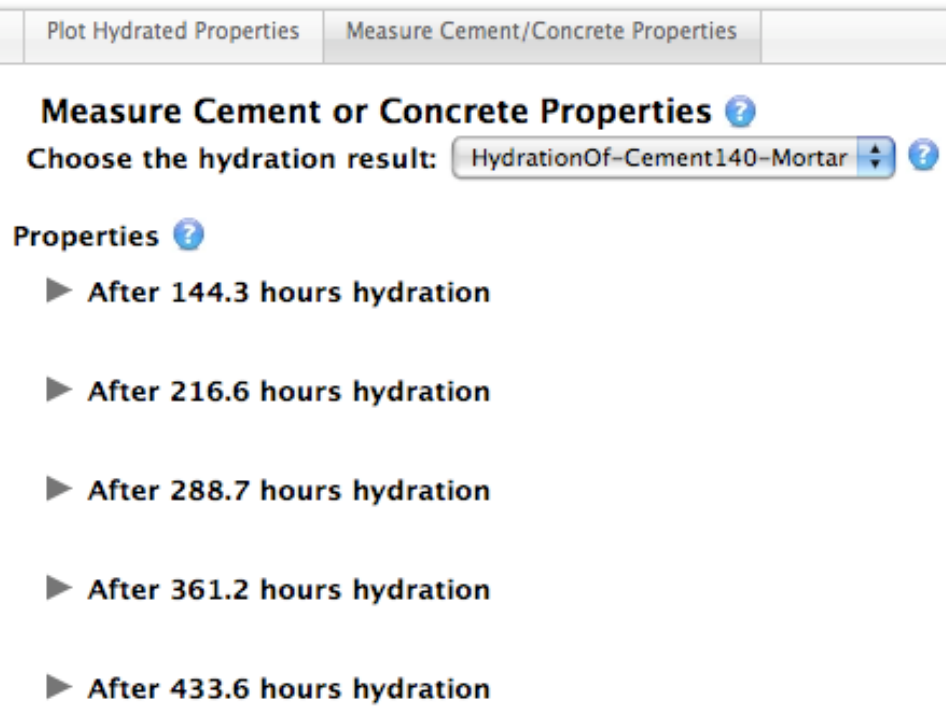

When one of these individual sections is expanded, it reveals two buttons, one to calculate the elastic properties (effective linear elastic moduli) and one to calculate the transport properties (effective diffusivity). Clicking on these buttons launches the finite element models that calculate these properties on the digital image [Garboczi 1998].

$\nabla$ After 651.5 hours hydration

Elastic Properties

Measure Elastic Moduli

Transport Properties

Measure Transport Factor

The finite element calculations take significant computational time to complete, about 20 minutes to 30 minutes for a typical $100 \times 100 \times 100$ grid. Once the calculations begin, the relevant section of this page will display several boxes that will eventually contain the results of the calculations. While the calculations are ongoing, however, these boxes will display the message "Measuring...". The data that are displayed in these boxes when the calculations are completed is described now. 


\begin{tabular}{|l|}
\hline After 651.5 hours hydration \\
\hline Elastic Properties \\
\hline Measuring... \\
\hline Measuring... \\
\hline Measuring... \\
\hline Measure Elastic Moduli \\
\hline Transport Properties \\
\hline Measuring... \\
\hline Measure Transport Factor \\
\hline
\end{tabular}

\section{Elastic Properties Results}

There are three text boxes to display the elastic properties results:

- A summary of the effective elastic properties of the cement paste, including the bulk modulus, $\mathrm{K}$ in GPa, shear modulus, G in GPa, Young's modulus, $\mathrm{E}$ in $\mathrm{GPa}$, and Poisson ratio, $v$. If the material is a mortar or concrete, this box will also display the effective elastic properties of the mortar or concrete. These latter properties are calculated with Differential Effective Medium Theory (D-EMT) [Garboczi and Berryman 2001], and include the effective K, G, E, and $v$. The D-EMT model takes the cement paste elastic properties, aggregate elastic properties, and the properties of the ITZ (also gleaned from the finite element calculations on the cement paste near the aggregate surface, as described below), as well as the volume fractions of the paste, aggregates, and air voids. In addition to these properties, a mortar or concrete will also have the estimated compressive strength displayed in the box, in $\mathrm{MPa}$, which is estimated from the empirical relationship between Young's Modulus and compressive strength described by Neville [Neville 1995].

- The second box shows the relative contribution to the elastic properties of each phase in the microstructure. For each phase in turn, the following data are provided: (1) the volume fraction of the phase, (2) the mean value, over all the voxels of the given phase, of the bulk modulus 
calculated using the linear elastic relation between the local stress and the macroscopically applied strain, (3) the fraction that this value is of the total effective bulk modulus of the material; (4) and (5) are the same quantities calculated for the shear modulus; (6) and (7) are the same quantities calculated for the Young's modulus.

- The third box contains information about the variation of the elastic properties of the cement paste as a function of distance perpendicular to the aggregate surface. The data appear in five columns, identified here as (1) distance from the aggregate in $\mu \mathrm{m}$, (2) K for the paste (GPa), (3) G for the paste (GPa), (4) E for the paste (GPa), and (5) $v$ for the paste. These data are calculated directly from the finite element model results and are used to determine the elastic properties of the ITZ. The ITZ properties are determined by averaging these data over thicknes of the ITZ, which is approximately equal to the median particle size of the starting cement powder [Bentz and Garboczi 1999b].

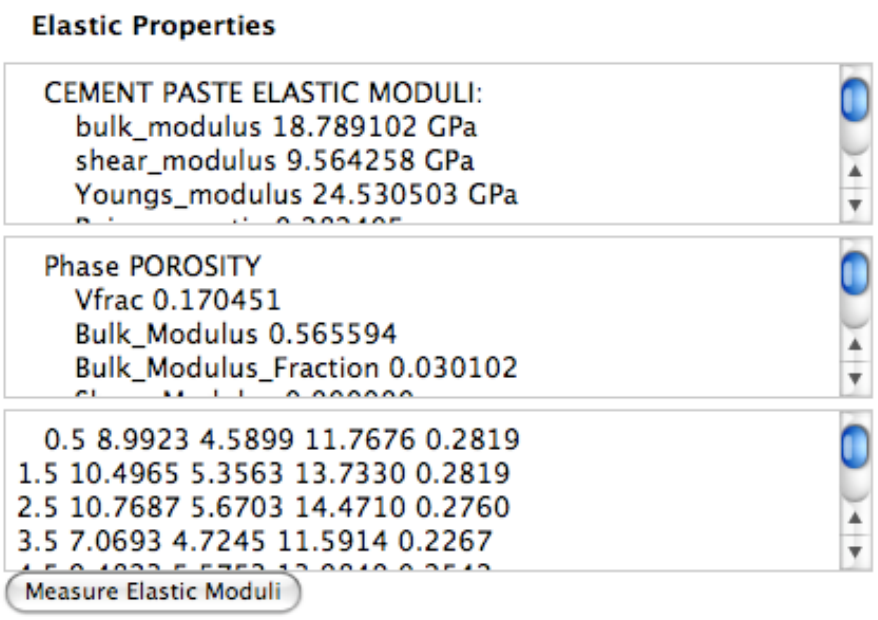

\section{Transport Properties Results}

Calculated transport properties are all displayed in one box, and consist of the relative diffusion coefficient in the $\mathrm{x}, \mathrm{y}$, and $\mathrm{z}$ directions. Here the relative diffusion coefficient is defined as the effective diffusion coefficient of mobile solution species in the material, divided by the diffusion coefficient of the same species in pure pore solution of the same composition. In addition, the average relative diffusion coefficient over all three dimensions and the formation factor are displayed in the text box. The formation factor is the inverse of the average relative diffusion coefficient as defined here. 
My Operations

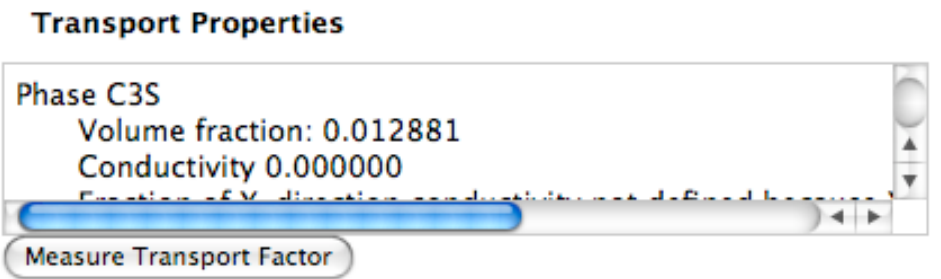

Following the value of the formation factor, the text box displays phase-specific information similar to that displayed for elastic properties above. . For each phase in turn, the following data are provided: (1) the volume fraction of the phase, (2) the relative conductivity of the phase, that is, the conductivity of mobile species through the phase itself divided by the conductivity of the same species through pure pore solution of the same composition; saturated porosity has a relative conductivity of 1.0 by definition, and solid dense phases have a relative conductivity of 0.0 , (3) the fraction that this phase contributes to the overall effective conductivity of the composite materials in each orthogonal direction.

\section{My Operations}

The "My Operations" page is the central location for checking the status of a user's operations. This guide has already discussed all of the major operations that can be executed in eVCCTL, but now is a good time to list all the types in summary.

Microstructure: Creation of a cement paste microstructure

Aggregate: Creation of a mortar or concrete aggregate packing

Hydration: Simulating the hydration of a cement paste

Elastic-moduli: Calculation of elastic moduli of a cement paste, mortar, or concrete

Transport-factor: Calculation of relative diffusion coefficients and formation factor

On the "My Operations" page, each operation for a user is listed in one of four sections, depending on their status: queued, running, finished, or canceled.

\section{Queued operations}

When an operation is requested on one of the eVCCTL pages, it is given an entry in the database and is placed in a queue waiting to be run. Some operations will leave the queue and begin running almost immediately, but some others, such as hydration operations waiting for their microstructure to be created, will remain in the queue for some time. While in the queue, a new directory is created to store the 
results, and an input file is created for the $C$ program that will process the input and generate the results. On the "My Operations" page, operations in the queue appear in a yellow table at the top of the page, with information about the type of operation

Queued operations
\begin{tabular}{|c|c|c|c|}
\hline Name & Type & Time queued & \\
\hline HydrationOf-Cement140-Paste & Hydration & 16 May 2010 22:13:38 & Delete \\
\hline
\end{tabular}

(see the previously enumerated list for types) and the time of the request displayed.

At the right of the entry is a link to delete the operation from the queue.

Clicking on the "Delete" link will remove the operation request from the database and delete the directory associated with the operation.s

\section{Running operations}

While an operation is running, it appears in a green table in this section. The name of the operation appears as a link. If the name is clicked, the "My Files" page is opened to the operation in question so the user can examine the files that have been generated for the operation. See Section 10 for more detail on the "My Files" page. In addition to the name, the operation type and the time started are displayed.

\begin{tabular}{|c|c|c|c|}
\hline Name & Type & Time started & \\
\hline Cement140-Paste & Microstructure & 16 May 2010 22:13:32 & Cancel \\
\hline
\end{tabular}

At the right of the entry is a link to cancel the operation. Clicking on the "Cancel" link will terminate the C program that is running the operation, and the operation will be moved to the "Canceled operations" section of the page. The input and output files associated with the operation will remain intact.

\section{Finished operations}

When the C program responsible for running an operation has finished (either successfully or unsuccessfully), the operation is moved from the "Running operations" section to this section. It appears as an entry in a blue table. As before, the name of the operation appears as a link that redirects the page to the operation's entry in the "My Files" page. In addition to the name, the operation type is displayed, as well as the time the operation started and finished.

At the right of each entry is a link to delete the finished operation. Clicking on the "Delete" link will remove the operation's listing from the database. All input and output files associated with the operation also will be removed from the computer.

Note: The deletion of an operation cannot be undone, so use this feature with caution. 


\begin{tabular}{|l|l|l|l|l|}
\hline \multicolumn{1}{|c|}{ Name } & \multicolumn{1}{|c|}{ Type } & \multicolumn{1}{|c|}{ Time started } & \multicolumn{1}{|c|}{ Time finished } & \\
\hline $\begin{array}{l}\text { HydrationOf-Cement152- } \\
\text { Mortar/Transport-factor-9 }\end{array}$ & $\begin{array}{l}\text { Transport- } \\
\text { factor }\end{array}$ & $\begin{array}{l}16 \text { May 2010 } \\
20: 08: 12\end{array}$ & $\begin{array}{l}16 \text { May 2010 } \\
20: 11: 05\end{array}$ & Delete \\
$\begin{array}{l}\text { HydrationOf-Cement152- } \\
\text { Mortar/Elastic-moduli-9 }\end{array}$ & Elastic-moduli & $\begin{array}{l}16 \text { May 2010 } \\
20: 08: 07\end{array}$ & $\begin{array}{l}16 \text { May 2010 } \\
20: 43: 34\end{array}$ & Delete \\
\hline
\end{tabular}

\section{Canceled operations}

If a running operation is canceled, its entry appears in this pink table. In eVCCTL, the operation cannot be restarted, but it can be deleted. Clicking on the "Delete" link at the right of the entry will remove the operation's listing from the database and will also remove all input and output files associated with the operation from the computer. The deletion of a canceled operation cannot be undone.

\begin{tabular}{|c|c|c|c|c|}
\hline Name & Type & Time started & Time cancelled & \\
\hline Cement140-Paste & Microstructure & 16 May 2010 22:13:32 & 16 May 2010 22:15:02 & Delete \\
\hline
\end{tabular}

\section{My Files}

Other than the "Measurements" page, the "My Files" page is the main location for viewing the progress and results of an operation. The input and output files associated with an operation can be viewed here or optionally exported to the computer's Desktop for further examination.

The "My Files" page has five sections, one for each type of operation (see the enumerated list at the beginning of Section 9 for a listing of the operation types). Each of these sections displays the name of every operation of that type that is recorded in the database, regardless of whether the operation is queued, running, finished, or canceled. Deleted operations do not appear.

The name of a given operation is actually the heading of a collapsed field that can be expanded by clicking on the small grey triangle next to the operation name. Expanding a section reveals a three-column table listing all the input and output files associated with the operation, along with a short description of the file contents and options for viewing or exporting the file. A link appears at the end of each table to export all of the files at once in a single compressed archive to your Desktop or Downloads folder. 
My Operations

\subsection{Microstructure Operations}

Finished microstructure operations have seven or eight associated files, each of which is briefly described here.

\section{Cement152-Mortar}

\begin{tabular}{|l|l|l|}
\hline \multicolumn{1}{|c|}{ File } & \multicolumn{1}{|c|}{ Description } & \multicolumn{1}{c|}{ Content } \\
\hline ASTM-C109.gdg & Grading & Show Export \\
Cement152-Mortar.bias & One-pixel bias numbers & Show Export \\
Cement152-Mortar.img & Microstructure image & Show Export \\
Cement152-Mortar.img.in & Input to genmic & Show Export \\
Cement152-Mortar.img.out & Output from genmic & Show Export \\
Cement152-Mortar.img.struct & Particle SH coefficients & Show Export \\
Cement152-Mortar.pimg & Particle image file & Show Export \\
Cement152-Mortar.stt & Cement phase statistics & Show Export \\
\hline
\end{tabular}

Export all files for this operation in one zip file: Cement152-Mortar.zip

Grading: A text file containing the aggregate grading specified when creating a mortar or concrete. This entry will not be present for cement pastes. The contents of this file, and any other simple text file, can be displayed in a scrolling text box by clicking on the "Show" link at the right of the entry. It consists of three columns: (1) the common name of the sieve, (2) the sieve opening size (in mm), and (3) the mass fraction of aggregate retained in the sieve. The text box can be hidden again by clicking on the "Hide" link. Of course, this or any other file on the "My Files" page can be exported to the Desktop or Downloads folder by clicking on the "Export" link.

\begin{tabular}{|c|c|c|c|c|}
\hline File & Description & \multicolumn{3}{|c|}{ Content } \\
\hline \multirow[b]{2}{*}{ ASTM-C109.gdg } & \multirow[b]{2}{*}{ Grading } & \multicolumn{3}{|c|}{ Hide Export } \\
\hline & & $\begin{array}{l}\text { Sieve } \\
\text { No. } 5 \\
\text { No. } 6 \\
\text { No. } 7 \\
\therefore \text { ? }\end{array}$ & $\begin{array}{lc}\text { DiamMass_frac } \\
4.000 & 0.0 \\
3.350 & 0.0 \\
2.800 & 0.0 \\
& \end{array}$ & $\begin{array}{l}0 \\
\text {. }\end{array}$ \\
\hline $\begin{array}{l}\text { Cement152- } \\
\text { Mortar.bias }\end{array}$ & $\begin{array}{l}\text { One-pixel bias } \\
\text { numbers }\end{array}$ & \multicolumn{3}{|c|}{ Show Export } \\
\hline
\end{tabular}


One-pixel bias numbers: Cement paste microstructures in eVCCTL have a resolution of $1 \mu \mathrm{m}$, but a large number of cement particles are smaller than this minimum feature size. To include these particles in the virtual microstructure, they are represented as $1 \mu \mathrm{m}$ clusters of smaller particles. These clusters should have a higher surface area and, consequently, a greater rate of reaction with water than a single particle of the same size. The one-pixel bias numbers, calculated from knowledge of the cement particle size distribution in the submicrometer range, are included in this file as a triplet of numbers, one number on each row, for each phase in the initial microstructure. The triplet is formatted as follows:

The first number in the triplet is always 0 , for reasons having to do the the legacy versions of the software.

The second number in the triplet is the bias value, a decimal number typically near 1.0, but which may be significantly greater than 1.0 for fine cements, or slightly less than 1.0 for coarse cements.

The third number in the triplet is the integer identification number of the phase. Appendix I lists the identification numbers for the phases.

Microstructure image: This file contains a listing of the phase occupying each voxel in the 3D virtual microstructure. The file has a five-line header with selfdescriptive entries, followed by the integer phase identification number for each voxel in the grid, with one voxel per row. Ordinarily, the text version of this file will hold little interest to the user. Therefore, clicking on the "Show" link will cause a thumbnail color image of a 2D slice from the microstructure to display. Please refer to Section 10.2 for more information on working with these images.

Input to genmic: This is the input file read by the $\mathrm{C}$ program (genmic) that creates the virtual microstructure. It is difficult to read because it is not annotated in any way. More sense can be made of the input file by viewing it in conjunction with the output file, the latter which provides a running commentary on the types of input being read.

Output from genmic: This is the output file produced by the $\mathrm{C}$ program (genmic) as it runs, especially describing the nature of the input values that are read. Note: Ordinarily, the output file will be of little interest, but it can provide important clues to the cause of any failure of the program to execute properly. If genmic fails for some reason, an error message will typically appear near the end of the output file.

Particle SH coefficients: A listing of the coefficients in the spherical harmonic (SH) expansion describing the shape of each particle in the microstructure. This file probably is of no interest to users of eVCCTL.

Particle image file: This file is a complement to the microstructure image file. Whereas the microstructure image associates a unique phase identification number to each voxel, the particle image file associates a particle number to each voxel. Specifically, a voxel is assigned a number $n$ if the phase at that voxel belongs to the nth particle in the microstructure. Porosity is assigned the number zero, and particles comprised of only one voxel also are assigned zero. This file is used 
internally by the $\mathrm{C}$ program responsible for hydration operations (disrealnew) and should hold no interest for users of eVCCTL.

Cement phase statistics: A tabular display of the number of voxels assigned to each phase in the final microstructure, along with the corresponding mass fraction, volume fraction, and surface area fraction of that phase in the virtual microstructure. This file consists of two sections. The first eight lines of the file display the phase statistics on a total clinker solid basis. This section can be used to determine how closely the final microstructure reproduces the clinker phase fractions and $\mathrm{w} / \mathrm{b}$ ratio that were requested when the operation was launched. The remaining part of the file lists four values for each phase

- The number of voxels assigned to that phase

- The number of voxel faces of that phase that are adjacent to porosity; this is the digitized analog of the surface area.

- The volume fraction of the phase in the microstructure, on a total volume basis (solids plus porosity)

- $\quad$ The mass fraction of the phase in the microstructure, on a total mass basis (solids plus porosity)

\subsection{Displaying Microstructure Images}

As already described, microstructure images are displayed as color 2D slices of the 3D microstructure. eVCCTL provides the ability to view the microstructure at different magnifications and from different perspectives, so we now devote attention to explaining these features.

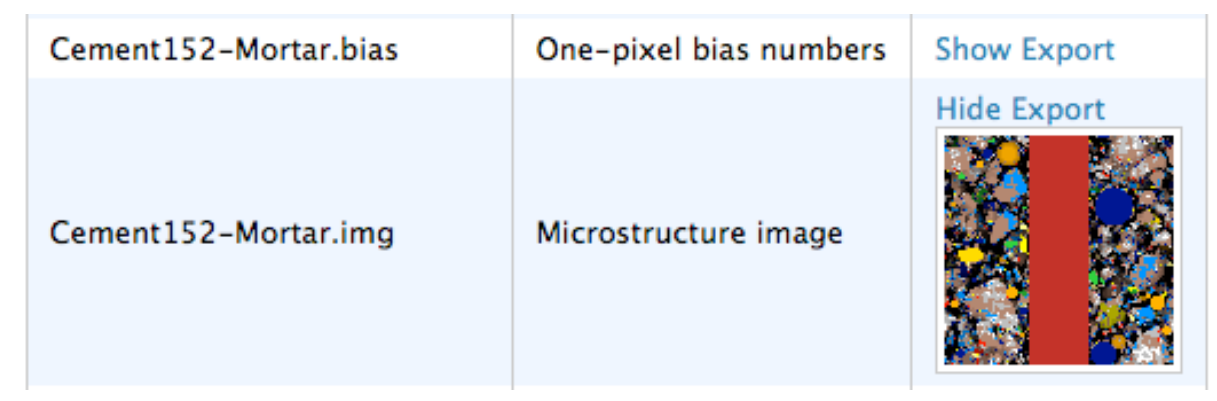

Clicking on the "Show" link for any microstructure image file displays a thumbnail image of a $2 \mathrm{D}$ cross section from the $3 \mathrm{D}$ virtual microstructure. Note that it may take several seconds for this image to display because it is being created at the time of the "Show" request.

The thumbnail is a color image, with each color corresponding to a different phase in the mix. A red vertical stripe through the center of the image represents a flat "slab" of aggregate, which is necessary for simulating the packing effects in the ITZ, as mentioned in an earlier section. The aggregate slab will be present only if coarse or fine aggregate was requested in the mix.

Once the thumbnail is displayed, it can be clicked with the mouse to open another page for more detailed examination and manipulation of the image. 


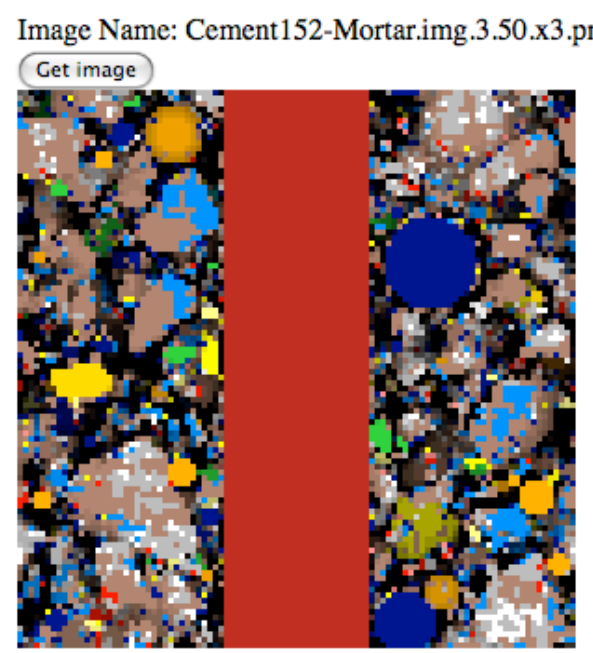

-Legend
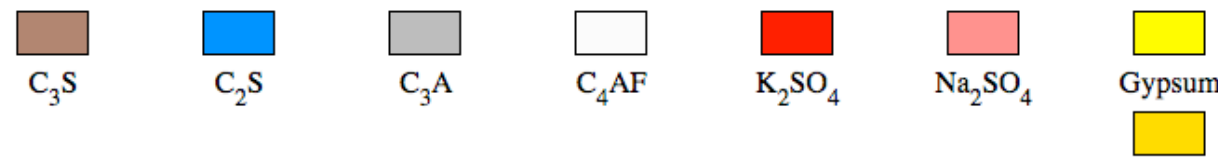

Hemihydrate

Plane to view: Choose one of three orthogonal directions from which to view the microstructure. The viewing planes are defined by the two Cartesian coordinate axes they contain (e.g., the yz plane is the plane observed when viewing along the $\mathrm{x}$-axis).

Slice to view: Changing this value enables the user to view the image at different locations along the axis of viewing. Valid values are in the interval $\left[0, \mathrm{~L}_{\mathrm{x}}-1\right]$, where $L_{x}$ is the number of voxels in the direction being viewed. Values outside the valid interval are converted to the nearest value in the valid interval. For example, a slice value of -7 would be converted to 0 .

Magnification: A positive integer value of $M$ displays the image with $\mathrm{M} \times \mathrm{M}$ image pixels corresponding to each voxel in the microstructure. Note: the magnification value must be a positive integer. A non-integer value will throw an error.

Once the viewing options are selected, click on the "Get image" button or just press the Enter key on the keyboard to view the new image. Images previously viewed while this page has been open can be accessed by clicking the "Back" button on your browser. Continued clicking of the browser's "Back" button will return to the "My Files" page.

Underneath the displayed image is a key showing the colors assigned to each phase in the microstructure. The color key is quite similar to that used to view cements on the "Lab Materials" page, described in Section 6.1. 
My Operations

\subsection{Aggregate Operations}

Finished aggregate packing operations have seven associated files, each of which is briefly described here.

\begin{tabular}{|c|c|c|}
\hline File & Description & Content \\
\hline aggpack.in & Input to genaggpack & Show Export \\
\hline aggpack.out & Output from genaggpack & Show Export \\
\hline Aggregate.img & Microstructure image & Show Export \\
\hline Aggregate.img.struct & Particle SH coefficients & Show Export \\
\hline Aggregate.stt & Cement phase statistics & Show Export \\
\hline oneimage.input & & Show Export \\
\hline oneimage.output & & Show Export \\
\hline
\end{tabular}

Export all files for this operation in one zip file: AggregateFiles.zip

Input to genaggpack: This is the input file read by the $\mathrm{C}$ program (genaggpack) that creates the virtual microstructure. It is difficult to read because it is not annotated in any way. More sense can be made of the input file by viewing it in conjunction with the output file, the latter which provides a running commentary on the types of input being read.

Output from genaggpack: This is the output file produced by the $\mathrm{C}$ program (genaggpack) as it runs, especially describing the nature of the input values that are read. Note: Ordinarily, the output file will be of little interest, but it can provide important clues to the cause of any failure of the program to execute properly. If genaggpack fails for some reason, an error message will typically appear near the end of the output file.

Microstructure image: This file contains a listing of the phase occupying each voxel in the 3D virtual microstructure. In contrast to cement paste microstructures, an aggregate packing has either two or three phases present. Porosity and aggregate are always present. In addition, if the resolution of the packing is sufficiently fine that the ITZ can be resolved, it will appear as a separate phase for easy visualization. Clicking on the "Show" link will cause a thumbnail color image of a 2D slice from the microstructure to display. Please refer to Section 10.2 for more information on working with these images.

Particle SH coefficients: A listing of the coefficients in the spherical harmonic (SH) expansion describing the shape of each particle in the packing. This file is of no immediate interest to users of eVCCTL.

Phase statistics: A tabular display of the number of voxels assigned to each phase in the final packing. There is one line for porosity, one line for aggregate, and 
one line for ITZ. A value of zero for ITZ does not mean that there is no ITZ in the mortar or concrete, but instead means that the virtual packing was created at too coarse a resolution to include the ITZ in the image.

Besides these five files, a "oneimage.input" file and a "oneimage.output" file are also present in the table. These are used in the auxiliary program to render the aggregate packing image, and are of no interest to eVCCTL users.

\subsection{Hydration Operations}

Finished hydration operations often have a dozen or more associated files.

Cement alkali characteristics: Contains information on both the total and the readily-soluble potassium and sodium in the cement. The format and viewing of this file were discussed in Section 6.1.

Fly ash alkali characteristics: This file is required even if the material does not contain any fly ash. Its format is identical to that for the cement alkali characteristics file.

Hydration image: There will likely be 10 or more of this type of file in the list. Each one is a saved 3D microstructure at a different time during hydration. The actual number of this type of file depends on the time interval that was specified between successive outputs and on the total simulated time. For example, if a user requests hydration for $28 \mathrm{~d}(672 \mathrm{~h})$ with microstructure output every $72 \mathrm{~h}$, there will be 10 hydration images $(72$ h, 144 h, 216 h, 288 h, 360 h, 432 h, 504 h, 576 h, $648 \mathrm{~h}$, and a final microstructure at $672 \mathrm{~h}$ when the run finishes). All but the final hydration image files has the following pattern for its name

where

$$
\text { MicrostructureName.img.xxx.xxh.TT.0yz }
$$

- MicrostructureName is the name given to the initial microstructure (i.e. the microstructure operation name)

- $\quad x x x . x x h$ is the number of hours (to the nearest $0.01 \mathrm{~h}$ ) of hydration to which this image corresponds. Note: The exact time at which the microstructure is output is as close to the desired time interval as possible, but the elapsed time of each hydration cycle is not constant and so output at the exact time interval requested is rarely possible.

- $\quad$ TT is the initial temperature used for the hydration operation, in degrees Celsius

- $y$ is 0 if isothermal conditions were specified, or is 1 if adiabatic or semiadiabatic conditions were specified

- $\quad \mathrm{z}$ is 0 if hydrating under saturated conditions, or is 1 if hydrating under sealed conditions. 
My Operations

\begin{tabular}{|c|c|c|}
\hline File & Description & Content \\
\hline alkalichar.dat & Cement alkali characteristics & Show Export \\
\hline alkaliflyash.dat & Fly ash alkali characteristics & Show Export \\
\hline Cement152-Mortar.img.144.26h.25.001 & Hydration image & Show Export \\
\hline Cement152-Mortar.img.216.78h.25.001 & Hydration image & Show Export \\
\hline Cement152-Mortar.img.289.20h.25.001 & Hydration image & Show Export \\
\hline Cement152-Mortar.img.361.29h.25.001 & Hydration image & Show Export \\
\hline Cement152-Mortar.img.433.57h.25.001 & Hydration image & Show Export \\
\hline Cement152-Mortar.img.505.68h.25.001 & Hydration image & Show Export \\
\hline Cement152-Mortar.img.577.93h.25.001 & Hydration image & Show Export \\
\hline Cement152-Mortar.img.650.22h.25.001 & Hydration image & Show Export \\
\hline Cement152-Mortar.img.72.14h.25.001 & Hydration image & Show Export \\
\hline HydrationOf-Cement 152-Mortar.data & Hydration results & Show Export \\
\hline HydrationOf-Cement152-Mortar.hyd.in & Input to disrealnew & Show Export \\
\hline HydrationOf-Cement152-Mortar.hyd.out & Output from disrealnew & Show Export \\
\hline HydrationOf-Cement152-Mortar.img.25.001 & Hydration image & Show Export \\
\hline image_index.txt & & Show Export \\
\hline parameter_file.prm & Parameters file & Show Export \\
\hline slagchar.dat & Slag characteristics & Show Export \\
\hline
\end{tabular}

Export all files for this operation in one zip file: HydrationOf-Cement152-Mortar.zip

As an example, a hydrated image name of MyMic . img . 289 . 20h . 25 . 001 means the original microstructure is named MyMic . img, the microstructure was output at $289.20 \mathrm{~h}$ of hydration time, the initial temperature was $25^{\circ} \mathrm{C}$, and isothermal and saturated conditions were used.

The exception to this naming pattern is the final image that is written when the hydration operation terminates. This final image has the pattern

where

$$
\text { HydrationName.img.TT.0yz }
$$

- HydrationName is the name given to the hydration operation when it was launched. It should be the same as the heading for the table

- TT is the initial temperature used for the hydration operation, in degrees Celsius

- $y$ is 0 if isothermal conditions were specified, or is 1 if adiabatic or semiadiabatic conditions were specified

- $\quad \mathrm{z}$ is 0 if hydrating under saturated conditions, or is 1 if hydrating under sealed conditions. 


\section{My Operations}

For any of the hydration images, clicking on the "Show" link will cause a thumbnail color image of a 2D slice from the microstructure to display. Please refer to Section 10.2 for more information on working with these images.

Input to disrealnew: This is the input file read by the $\mathrm{C}$ program (disrealnew) that performs the virtual hydration operation. It is difficult to read because it is not annotated in any way. More sense can be made of the input file by viewing it in conjunction with the output file, the latter which provides a running commentary on the types of input being read.

Output from disrealnew: This is the output file produced by the $\mathrm{C}$ program (disrealnew) as it runs, especially describing the nature of the input values that

are read. Note: Ordinarily, the output file will be of little interest, but it can provide important clues to the cause of any failure of the program to execute properly. If disrealnew fails for some reason, an error message will typically appear near the end of the output file.

Image_index.txt: This is a two-column text file. The left column gives the times at which the hydration images were output, and the right column contains the full path name to the hydration image in question. Ordinarily, this file will be of no interest to the user, because any or all the images can be exported to the Desktop or Downloads folder by clicking on the "Export" link.

Parameters file: A listing of the several dozen parameters used by the $\mathrm{C}$ program (disrealnew) in its execution. These parameters cannot be modified by the user.

Slag characteristics: Contains information the physical and chemical characteristics of the slag, and the slag hydration products, used in the microstructure. This file must be input to the hydration operation even if no slag is present in the microstructure. The format and viewing of this file were discussed in Section 6.2 .

Hydration Results: A large tabular display of the values of the 61 hydration properties at each computational cycle. This file has 63 columns and several hundred rows, making it difficult to view in the small text box that is provided when the "Show" button is clicked. It is much more convenient to Export the file to the Desktop and then import the table into a spreadsheet application. Also, recall that any one or more of the properties in this file can be simultaneously plotted on the Measurements page of eVCCTL.

The meaning of each of the 63 columns in the hydration results file is provided in Appendix II.

\subsection{Mechanical properties operations}

Finished mechanical properties operations have five associated files, each of which is briefly described here. 
My Operations

\begin{tabular}{|c|c|c|}
\hline File & Description & Content \\
\hline EffectiveModuli.dat & Effective moduli results & Show Export \\
\hline elastic.in & Input to elastic & Show Export \\
\hline elastic.out & Output from elastic & Show Export \\
\hline ITZmoduli.dat & ITZ elastic characteristics & Show Export \\
\hline PhaseContributions.dat & Phase contributions & Show Export \\
\hline
\end{tabular}

Export all files for this operation in one zip file: Elastic-moduli-9.zip

Input to elastic: This is the input file read by the $C$ program (elastic) that performs both the finite element calculations of the effective elastic moduli of cement paste and, for mortar or concrete, the effective medium theory calculations of the effective moduli and compressive strength of the material. This file has only a few lines, but it is not easy to understand because it is not annotated. More sense can be made of the input file by viewing it in conjunction with the output file, the latter which provides a running commentary on the types of input being read.

Output from elastic: This is the output file produced by the $C$ program (elastic) as it runs, especially describing the nature of the input values that are read. Note: Ordinarily, the output file will be of little interest, but it can provide important clues to the cause of any failure of the program to execute properly. If elastic fails for some reason, an error message will typically appear near the end of the output file.

Effective moduli results: This file is displayed in the first text box on the Measurements page when a mechanical property operation is finished. Its format is described in Section 8.2.

Phase contributions: This file is displayed in the second text box on the Measurements page when a mechanical property operation is finished. Its format is described in Section 8.2.

ITZ elastic characteristics: This file is present only if aggregate has been included in the mix (i.e., only for a mortar or concrete). It is displayed in the third text box on the Measurements page when a mechanical property operation is finished. Its format is described in Section 8.2.

\subsection{Transport properties operations}

Finished transport properties operations have four associated files, each of which is briefly described here.

Input to dc3d: This is the input file read by the C program ( $d c 3 d$ ) that performs both the finite difference calculations of the effective relative diffusion coefficients and formation factor of the given microstructure image. This file has 
My Operations

V HydrationOf-Cement152-Mortar/Transport-factor-9
\begin{tabular}{|l|l|l|}
\hline \multicolumn{1}{|c|}{ File } & \multicolumn{1}{|c|}{ Description } & \multicolumn{1}{|c|}{ Content } \\
\hline dc3d.in & Input to dc3d & Show Export \\
dc3d.out & Output from dc3d & Show Export \\
TransportFactorOutput.dat & Major transport output data & Show Export \\
TransportFactorResults.dat & Transport factor results & Show Export \\
\hline
\end{tabular}

Export all files for this operation in one zip file: Transport-factor-9.zip

only a few lines, but it is not easy to understand because it is not annotated. More sense can be made of the input file by viewing it in conjunction with the output file, the latter which provides a running commentary on the types of input being read.

Output from dc3d: This is the output file produced by the $C$ program (dc3d) as it runs, especially describing the nature of the input values that are read. Note: Ordinarily, the output file will be of little interest, but it can provide important clues to the cause of any failure of the program to execute properly. If $\mathrm{dc} 3 \mathrm{~d}$ fails for some reason, an error message will typically appear near the end of the output file.

Major transport output data: This file contains rather verbose output from the dc3d program, including the status of the conjugate gradient relaxation method [Garboczi 1998] at the end of each iteration. Ordinarily, this file will hold no interest for the user.

Transport factor results: This file is displayed in the text box on the Measurements page when a transport property operation is finished. Its format is described in Section 8.2.

\section{Logout}

To gracefully log out of the eVCCTL system, click on the "Logout" tab in the main menu bar. This logs you out immediately and also takes you to the original login page for the system, where you can switch to a new user.

Note: If you wish to shut down eVCCTL and close the browser, as explained in Section 3.1, you must also

- Wait for all running operations to finish, or cancel all running operations

- $\quad$ Close the web browser

- Open the Java console window and press Ctrl-C. After a brief pause, you will be asked, "Terminate batch job ( $\mathrm{Y} / \mathrm{N})$ ?". Type "y" and press the Enter button. The Java console window will close. 
Appendix I: Phase Identification Numbers

\section{Appendix I}

This appendix gives the integer identification number and the short display name that is used in eVCCTL for each phase that is recognized in the system.

\begin{tabular}{|c|c|c|}
\hline Phase Name & Display Name & ID \\
\hline Saturated porosity & POROSITY & 0 \\
\hline $\mathrm{C}_{3} \mathrm{~S}$ (alite) & C3S & 1 \\
\hline $\mathrm{C}_{2} \mathrm{~S}$ (belite) & $\mathrm{C} 2 \mathrm{~S}$ & 2 \\
\hline $\mathrm{C}_{3} \mathrm{~A}$ (cubic tricalcium aluminate) & C3A & 3 \\
\hline $\mathrm{C}_{4} \mathrm{AF}$ (tetracalcium aluminoferrite) & $\mathrm{C} 4 \mathrm{AF}$ & 4 \\
\hline $\mathrm{K}_{2} \mathrm{SO}_{4}$ (arcanite) & $\mathrm{K} 2 \mathrm{SO} 4$ & 5 \\
\hline $\mathrm{Na}_{2} \mathrm{SO}_{4}$ (thenardite) & NA2SO4 & 6 \\
\hline $\mathrm{CaSO}_{4} \cdot 2 \mathrm{H}_{2} \mathrm{O}$ (gypsum) & GYPSUM & 7 \\
\hline $\mathrm{CaSO}_{4} \cdot 0.5 \mathrm{H}_{2} \mathrm{O}$ (hemihydrate or bassanite) & HEMIHYD & 8 \\
\hline $\mathrm{CaSO}_{4}$ (anhydrite) & ANHYDRITE & 9 \\
\hline Silica fume & SFUME & 10 \\
\hline Inert filler material & INERT & 11 \\
\hline Slag & SLAG & 12 \\
\hline Aggregate & INERTAGG & 13 \\
\hline Aluminosilicate glass (in fly ash) & ASG & 14 \\
\hline Calcium aluminosilicate glass (in fly ash) & CAS2 & 15 \\
\hline Amorphous silica ( $\mathrm{SiO}_{2}$ in fly ash) & AMSIL & 16 \\
\hline $\mathrm{C}_{3} \mathrm{~A}$ (in fly ash) & FAC3A & 17 \\
\hline CH (calcium hydroxide or portlandite) & $\mathrm{CH}$ & 19 \\
\hline C-S-H gel & $\mathrm{CSH}$ & 20 \\
\hline $\mathrm{C}_{3} \mathrm{AH}_{6}$ (hydrogarnet) & C3AH6 & 21 \\
\hline AFt (generic ettringite) & ETTR & 22 \\
\hline $\mathrm{AFt}$ formed from $\mathrm{C}_{4} \mathrm{AF}$ dissolution & ETTRC4AF & 23 \\
\hline AFm (generic monosulfate) & AFM & 24 \\
\hline $\mathrm{FH}_{3}$ & FH3 & 25 \\
\hline $\mathrm{C}-\mathrm{S}$-H formed from pozzolanic reactions & POZZCSH & 26 \\
\hline C-S-H formed from slag reactions & SLAGCSH & 27 \\
\hline $\mathrm{CaCl}_{2}$ & CACL2 & 28 \\
\hline $\mathrm{C}_{3} \mathrm{~A} \cdot \mathrm{CaCl}_{2} \cdot 10 \mathrm{H}_{2} \mathrm{O}$ (Friedel's salt) & FRIEDEL & 29 \\
\hline $\mathrm{C}_{2} \mathrm{ASH}_{8}$ (strätlingite) & STRAT & 30 \\
\hline $\mathrm{CaSO}_{4} \cdot 2 \mathrm{H}_{2} \mathrm{O}$ (secondary gypsum) & GYPSUMS & 31 \\
\hline $\mathrm{CaSO}_{4} \cdot 2 \mathrm{H}_{2} \mathrm{O}$ (absorbed gypsum; not used) & ABSGYPSUM & 32 \\
\hline
\end{tabular}




\begin{tabular}{|l|l|l|}
\hline Phase Name & Display Name & ID \\
\hline $\mathrm{CaCO}_{3}$ (calcite or aragonite or limestone) & CACO3 & 33 \\
\hline Calcium monocarboaluminate & AFMC & 34 \\
\hline $\mathrm{Mg}(\mathrm{OH})_{2}$ (brucite) & BRUCITE & 35 \\
\hline $\mathrm{MgSO}_{4}$ & MS & 36 \\
\hline $\mathrm{CaO}$ (free lime) & FREELIME & 37 \\
\hline $\mathrm{C}_{3} \mathrm{~A}-\mathrm{o}$ (orthorhombic $\left.\mathrm{C}_{3} \mathrm{~A}\right)$ & OC3A & 38 \\
\hline $\begin{array}{l}\text { Empty porosity resulting from drying (not } \\
\text { used) }\end{array}$ & DRIEDP & 53 \\
\hline Empty porosity from self-desiccation & EMPTYP & 55 \\
\hline Saturated porosity in a microcrack (not used) & CRACKP & 56 \\
\hline
\end{tabular}




\section{Appendix II}

This appendix provides a brief description of each column in the hydration results file (ending in . data; see Section 10.4 for more information)

\begin{tabular}{|c|c|c|}
\hline Column & Heading & Description \\
\hline 1 & Cycle & The computational cycle \\
\hline 2 & time(h) & The hydration time in hours \\
\hline 3 & Alpha_mass & Degree of hydration on a cement mass basis \\
\hline 4 & Alpha_fa_mass & $\begin{array}{l}\text { Degree of hydration of fly ash on a fly ash mass } \\
\text { basis }\end{array}$ \\
\hline 5 & Heat(kJ/kg_solid) & Heat produced ( $>0$ for exothermic, $\mathrm{kJ} / \mathrm{kg}$ of solids) \\
\hline 6 & Temperature(C) & Temperature of the system in degrees Celsius \\
\hline 7 & Gsratio & Paste gel-space ratio (see [Taylor 1997[) \\
\hline 8 & Wno(g/g) & $\begin{array}{l}\text { Non-evaporable water content (g water/g cement), } \\
\text { on an unignited cement mass basis }\end{array}$ \\
\hline 9 & Wni(g/g) & $\begin{array}{l}\text { Non-evaporable water content (g water/g cement), } \\
\text { on an ignited cement mass }\end{array}$ \\
\hline 10 & ChemShrink(mL/g) & Chemical shrinkage in mL/g of cement \\
\hline 11 & $\mathrm{pH}$ & Estimated pH of the capillary pore solution \\
\hline 12 & Conductivity & $\begin{array}{l}\text { Estimated DC conductivity of the pore solution, in } \\
\mathrm{S} / \mathrm{m}\end{array}$ \\
\hline 13 & {$[\mathrm{Na}+](\mathrm{M})$} & Estimated $\mathrm{Na}^{+}$concentration in solution, in $\mathrm{mol} / \mathrm{L}$ \\
\hline 14 & {$[\mathrm{~K}+](\mathrm{M})$} & Estimated $\mathrm{K}^{+}$concentration in solution, in mol/L \\
\hline 15 & {$[\mathrm{Ca}++](\mathrm{M})$} & Estimated $\mathrm{Ca}^{++}$concentration in solution, in mol/L \\
\hline 16 & [SO4-- $](\mathrm{M})$ & Estimated $\mathrm{SO}_{4}^{--}$concentration in solution, in mol/L \\
\hline 17 & $\{\mathrm{~K}+\}$ & $\begin{array}{l}\text { Estimated activity of } \mathrm{K}^{+} \text {in solution on a molal basis } \\
\text { (dimensionless) }\end{array}$ \\
\hline 18 & $\{\mathrm{Ca}++\}$ & $\begin{array}{l}\text { Estimated activity of } \mathrm{Ca}^{++} \text {in solution on a molal } \\
\text { basis (dimensionless) }\end{array}$ \\
\hline 19 & $\{\mathrm{OH}-\}$ & $\begin{array}{l}\text { Estimated activity of } \mathrm{OH}^{-} \text {in solution on a molal } \\
\text { basis (dimensionless) }\end{array}$ \\
\hline
\end{tabular}




\begin{tabular}{|l|l|l|}
\hline Column & Heading & Description \\
\hline 20 & $\{$ SO4-- $\}$ & $\begin{array}{l}\text { Estimated activity of } \mathrm{SO}_{4}^{--} \text {in solution on a molal } \\
\text { basis (dimensionless) }\end{array}$ \\
\hline 21 & Vfpore & Volume fraction of capillary pores \\
\hline 22 & Poreconnx & $\begin{array}{l}\text { Fraction of capillary pore volume that forms a } \\
\text { percolated network in the x direction }\end{array}$ \\
\hline 23 & Poreconny & $\begin{array}{l}\text { Fraction of capillary pore volume that forms a } \\
\text { percolated network in the y direction }\end{array}$ \\
\hline 24 & Poreconnz & $\begin{array}{l}\text { Fraction of capillary pore volume that forms a } \\
\text { percolated network in the z direction }\end{array}$ \\
\hline 25 & Poreconnave & Arithmetic mean of the previous three columns \\
\hline 26 & Solidconnx & $\begin{array}{l}\text { Fraction of solids that form a percolated } \\
\text { network in the x direction }\end{array}$ \\
\hline 27 & Solidconny & $\begin{array}{l}\text { Fraction of solids that form a percolated } \\
\text { network in the y direction }\end{array}$ \\
\hline 28 & Solidconnz & $\begin{array}{l}\text { Fraction of solids that form a percolated } \\
\text { network in the } \mathrm{z} \text { direction }\end{array}$ \\
\hline 29 & Solidconnave & Arithmetic mean of the previous three columns \\
\hline $30-63$ & Vfxxx & $\begin{array}{l}\text { Volume fraction of phase xxx on a system } \\
\text { volume basis, where xxx is the display name of } \\
\text { the phase given in } \text { Appendix I. }\end{array}$ \\
\hline
\end{tabular}




\section{Bibliography}

[ASTM 2008] Annual Book of ASTM Standards, vol. 04.01, American Society for Testing and Materials, West Conshohocken, PA, 2008.

[Bentz 1997] D.P. Bentz, "Three-dimensional computer simulation of cement hydration and microstructure development," J. Am. Ceram. Soc., 80 (1997) 3-21. http://concrete.nist.gov/monograph, Part I, Chapter 4, Section 2.

[Bentz 2005] D.P. Bentz, "CEMHYD3D: a three-dimensional cement hydration and microstructural development modelling package. Version 3.0," NISTIR 7232, U.S. Department of Commerce, June 2005. http://concrete.nist.gov/monograph, Appendix I-2.

[Bentz and Conway 2001], D.P. Bentz, J.T. Conway, "Computer modeling of the replacement of 'coarse' cement particles by inert fillers in low w/c ratio concretes: hydration and strength," Cem. Concr. Res., 31 (2001) 503-506. http://concrete.nist.gov/monograph, Part I, Chapter 4, Section 10a.

[Bentz and Feng 2000], D.P. Bentz, X. Feng, C.J. Haecker, P.E. Stutzman, "Analysis of CCRL proficiency cements 135 and 136 using CEMHYD3D," NISTIR 6545, U.S. Department of Commerce, 2000 1663-1671. http://concrete.nist.gov/monograph, Part I, Chapter 4, Section 3.

[Bentz and Garboczi 1991] D.P. Bentz, E.J. Garboczi, "Simulation studies of the effects of mineral admixtures on the cement paste-aggregate interfacial zone," ACI Mater. J., 88 (1991) 518-529. http://concrete.nist.gov/monograph, Part I, Chapter 6, Section 2.

[Bentz and Garboczi 1999] D.P. Bentz, E.J. Garboczi, C.J. Haecker, O.M. Jensen, "Effects of cement particle size distribution on performance properties of cementbased materials,” Cem. Concr. Res., 29 (1999) 1663-1671.

[Bentz and Garboczi 1999a] D.P. Bentz, E.J. Garboczi, "Effects of cement particle size distribution on early age autogenous strains and stresses in cement-based materials," Cem. Concr. Res, 29 (1999) 1663-1671. http://concrete.nist.gov/monograph, Appendix I-2.

[Bentz and Garboczi 1999b] D.P. Bentz, E.J. Garboczi, "Computer modelling of the interfacial transition zone microstructure and properties," in: M.G. Alexander, G. Arliguie, G. Ballivy, A. Bentur, J. Marchand (Eds.), Engineering and Transport Properties of the Interfacial Transition Zone in Cementitious Composites. RILEM Report No. 20, RILEM Publications, Cachan Cedex, France, 1999, pp. 349-385. http://concrete.nist.gov/monograph, Part I, Chapter 7, Section 15. 
[Bentz and Haecker 1999] D.P. Bentz, C.J. Haecker, "An argument for using coarse cements in high performance concretes," Cem. Concr. Res, 29 (1999) 615-618. http://concrete.nist.gov/monograph, Part I, Chapter 5, Section 8.

[Bentz and Jensen 2000] D.P. Bentz, O.M. Jensen, K.K. Hansen, J.F. Olesen, H. Stang, C.J. Haecker, "Influence of cement particles size distribution on early age autogenous strains and stresses in cement-based materials," J. Am. Ceram. Soc., 84 (2000) 129135. http://concrete.nist.gov/monograph, Part I, Chapter 8, Section 2.

[Bentz and Stutzman 1994] D.P. Bentz, P.E. Stutzman, "SEM analysis and computer modelling of hydration of portland cement particles," in: S.M. DeHayes, D. Stark (Eds.), Petrography of Cementitious Materials, American Society for Testing and Materials, Philadelphia, PA, 1994, pp. 60-73. http://concrete.nist.gov/monograph, Part I, Chapter 4, Section 1.

[Bentz and Stutzman 1999] D.P. Bentz, P.E. Stutzman, C.J. Haecker, S. Remond, "SEM/X-ray imaging of cement-based materials," in: H.S. Pietersen, J.A. Larbiz, H.H.A. Janssen (Eds.), Proceedings of the $7^{\text {th }}$ Euroseminar on Microscopy Applied to Building Materials, Delft University of Technology, 1999, pp. 457-466. http://concrete.nist.gov/monograph, Part I, Chapter 4, Section 1.

[Bullard and Garboczi 2006] J.W. Bullard, E.J. Garboczi, "A model investigation of the influence of particle shape on portland cement hydration," Cem. Concr. Res., 36 (2006) 1007-1015.

[Bullard and Stutzman 2006] J.W. Bullard, P.E. Stutzman, "Analysis of CCRL proficiency cements 151 and 152 using the Virtual Cement and Concrete Testing Laboratory," Cem. Concr. Res., 36 (2006) 1548-1555.

[Feng and Garboczi 2004] X. Feng, E.J. Garboczi, D.P. Bentz, P.E. Stutzman, T.O. Mason, "Estimation of the degree of hydration of blended cement pastes by a scanning electron microscope point-counting procedure," Cem. Concr. Res., 34 (2004) 1787-1793. http://concrete.nist.gov/monograph, Part I, Chapter 4, Section 2.

[Garboczi 1998] E.J. Garboczi, "Finite Element and Finite Difference Programs for Computing the Linear Electric and Elastic Properties of Digital Images of Random Materials," NISTIR 6269, U.S. Department of Commerce, December 1998. http://concrete.nist.gov/monograph, Part III, Chapter 2.

[Garboczi 2002] E.J. Garboczi, "Three-dimensional mathematical analysis of particle shape using x-ray tomography and spherical harmonics: application to aggregates used in concrete," Cem. Concr. Res., 32 (2002) 1621-1638. http://concrete.nist.gov/monograph, Part I, Chapter 10, Section 4. 
[Garboczi and Bentz 1999] E.J. Garboczi, D.P. Bentz, N.S. Martys, "Digital images and computer modelling," in: P-z. Wong (Ed.), Experimental Methods for Porous Media, Academic Press, San Diego, 1999, pp. 1-41. http://concrete.nist.gov/monograph, Appendix III.

[Garboczi and Bentz 2001] E.J. Garboczi, D.P. Bentz, "The effect of statistical fluctuation, finite size error, and digital resolution on the phase percolation and transport properties of the NIST cement hydration model," Cem. Concr. Res., 31 (2001) 1501-1514. http://concrete.nist.gov/monograph, Part I, Chapter 5, Section 1.

[Garboczi and Berryman 2001] E.J. Garboczi, J.G. Berryman, "Elastic moduli of a material containing composite inclusions: effective medium theory and finite element computations," Mech. Mater., 3e (2001) 455-470.

http://concrete.nist.gov/monograph, Part III, Chapter 7, Section 7.

[Garboczi and Bullard 2004] E.J. Garboczi, J.W. Bullard, "Shape analysis of a reference cement," Cem. Concr. Res., 34 (2004) 1933-1937.

http://concrete.nist.gov/monograph, Part I, Chapter 3, Section 7.

[Neville 1995] A.M. Neville, Properties of Concrete. Prentice-Hall, Harlow, England, 1995.

[Taylor 1997] H.F.W. Taylor, Cement Chemistry. $2^{\text {nd }}$ Edition. Thomas Telford, London, 1997. 